\title{
Correlation between homogeneous propane pyrolysis and pyrocarbon deposition
}

\author{
Cédric Descamps, \\ Gérard L. Vignoles*, \\ Olivier Féron, \\ Francis Langlais, \\ and Jérôme Lavenac
}

Laboratoire des Composites ThermoStructuraux

UMR 5801 (CNRS-SNECMA-CEA-UB1)

Université Bordeaux 1, 3, Allée La Boëtie

33600 Pessac, France

E-mail: vinhola@lcts.u-bordeaux1.fr

Revised manuscript submitted to Journal of the Electrochemical Society.

Suggested section. Electrochemical/Chemical Deposition and Etching

*to whom correspondence should be addressed 
Abstract. Pyrocarbon deposition through propane pyrolysis is studied in a 1-D hot-wall CVD furnace. The gas-phase pyrolysis is modelled with a partially reduced kinetic mechanism leading to polycyclic aromatic compounds (PAHs). The C2-C4 and C3 reaction paths are in competition for benzene formation. There is also an independent C3-C5 path leading to naphthalene. The gas-phase concentrations are correlated with experimental data including in-situ FTIR spectra intensities, pyrocarbon deposition rates, and pyrocarbon nanotextures. Rough Laminar pyrocarbon deposition appears to be more related to PAHs than Smooth Laminar pyrocarbon. 


\section{Introduction}

Aimed at high-temperature, high-performance structural applications, thermostructural composites are made of ceramic or carbon fibers, an interphase (usually carbon or hexagonal boron nitride) which coats the fibers, and a matrix which is again either ceramic or carbon. For aerospace applications, the matrix constituents are essentially pyrocarbon and less often refractory carbides such as silicon carbide $(\mathrm{SiC})$. Aircraft and F-1 racing car brakes are commonly made of carbon/carbon $(C / C)$ composites.

In order to elaborate the interphase and matrix, a common process is the Isothermalisobaric Chemical Vapor Infiltration (I-CVI)[1,2], involving low-pressure cracking of gaseous species (precursors), which are transported mainly by diffusion inside a fibrous preform, where heterogeneous reaction yields a solid deposit which densifies the preform [3]. The gaseous species used for the deposition are hydrocarbons, and silicon-bearing species such as silanes or chlorosilanes, possibly diluted in a carrier gas such as hydrogen, nitrogen, or argon.

The nanotexture of the deposited pyrocarbons is a key issue for the thermal properties of the composites. Depending on the degree of pyrocarbon anisotropy, one may switch from an isolating material (isotropic carbon) to a moderately conductive material (poorly anisotropic carbon), and to a very conductive material (highly anisotropic carbon) $[4,5]$. The mechanical behavior of the composites may also vary strongly. The conditions of interest in this study are the experimental conditions used in previous reports [6]: total pressure equal to $2 \mathrm{kPa}$, temperature between $900 K$ and $1400 K$, and pure propane as gaseous precursor. They yield only two kinds of nanostructure : the so-called Rough Laminar (RL) and Smooth Laminar (SL) nanotextures $[7,8]$. The former is much more anisotropic than the latter, with markedly different material properties, so the problem of interest is to be able to monitor experimental conditions suitable for the deposition of either one or the other nanotexture.

Past works on hydrocarbon pyrolysis in various conditions $[6,9,10]$ have led to the hypothesis of concurrent reaction pathways leading to different pyrocarbons. In- 
deed, the successive steps in hydrocarbon pyrolysis are $(i)$ a cracking of the initial molecules into more reactive and lighter gaseous species, $(i i)$ a recombination of these species up to the synthesis of light aromatic compounds, and (iii) an evolution of these aromatic compounds towards higher molecular weights like in a polymerization reaction. This evolution chain is called gas-phase maturation [10]. Subsequent evolutions depend on the experimental conditions : if a hot substrate is present, then pyrocarbon deposition occurs ; in the reverse case, soot formation predominates. Concerning pyrocarbon deposition, it has been shown that the hypothesis of two parallel reaction pathways starting from the gas phase and leading respectively to SL and RL pyrocarbons correctly accounts for the experimental results [11]. The choice between the predominance of one or the other reaction path relies on the degree of gas-phase maturation and on limitations by transport. Indeed, a more maturated gas phase leads to a rough laminar deposit. If the maturation is less advanced, the deposit is smooth laminar.

Our concern in this study is to obtain a more precise understanding of maturation effects, as well as of the possible deposition reaction pathways leading to SL and RL nanotextures. The first point requires an accurate description of the phenomena occurring in the gas-phase. Once the composition of the gas-phase above the substrate is known, it becomes possible to correlate it with deposition rates and the nanotexture of the deposits.

The assessment of the gas-phase composition during hydrocarbon pyrolysis is a key issue in numerous other engineering problems, such as sooting flames, olefin cracking, interstellar chemistry, etc ...; consequently, many research works have dealt with the production and study of detailed kinetic mechanisms. A similar approach, suited to the particular case of pyrocarbon CVD/CVI from pure propane, is set up and used in this work. A numerical study has been performed on the basis of previously published kinetic data, with a home-made 1D solver. In a first part, the modeling context will be presented, as well as the chemical model that has been used. Then, a comparison of the results with analysis of the gas phase by FTIR spectroscopy will be made, in order to provide a qualitative validation of the model. Finally, a correlation with deposition rates measurements and pyrocarbon deposit 
nanotextures data will lead us to set up a tentative explanation for the SL/RL transition.

\section{Model setup}

\subsection{Modeling context}

As our concern is primarily to correlate computational results to experimental data obtained in our laboratory with a long, narrow, tubular furnace, a home-made 1D solver was set up. Indeed, the small diameter of the furnace used for the FTIR validations implies that radial effects are of negligible importance [6]. Considering the weak inflow velocity involved in such a reactor, and the fact that there was no carrier gas, multicomponent diffusion has to be fully taken into account, so that the model may not be considered as a plug-flow model.

Each chemical species satisfies to a conservation equation which may be written as :

$$
\underbrace{\frac{\partial \rho_{i}}{\partial t}}_{\text {accumulation }}+\underbrace{\nabla \cdot\left(\rho_{i} \mathbf{v}\right)}_{\text {convection }}+\underbrace{\nabla \cdot\left(-\sum_{j} \mathrm{D}_{i j} \nabla \rho_{i}\right)}_{\text {diffusion }}=\underbrace{M_{i} R_{i}=M_{i} \sum_{k} k_{k} \prod_{j} c_{j}^{\nu_{j k}}}_{\text {chemical reactions }}
$$

A non-homogeneous temperature profile, as recorded experimentally [6], was assumed. The resolution of total mass balance equation gives the velocity profile along the furnace:

$$
\frac{\partial \rho}{\partial t}+\nabla \cdot(\rho \mathbf{v})=0
$$

All quantities are assumed to be radial averages.

The multicomponent diffusion coefficients were approximated using the bifurcation method [12], which avoids an explicit solving of the Stefan-Maxwell relationships. Since there is no stagnant point in the resolution domain, convergence problems owed to the quasi-singular diffusion matrix [13] are avoided.

An extra term should be added to the diffusion coefficients, which represents the effect of axial dispersion in the tube owed to radial discrepancies in axial velocity [14]. However, since it has been checked that its order of magnitude is always less than $1 / 10^{\text {th }}$ of the ordinary diffusion, it has been neglected. 
The inlet boundary conditions used for the model (see figure 1were a fixed inlet velocity $\mathbf{v}_{i n}$, and fixed partial densities $\rho_{i, i n}$. Actually, one should use Danckwerts boundary conditions for the species :

$$
\rho_{i, i n} \mathbf{v}_{i n}=\rho_{i} \mathbf{v}_{i n}-\nabla \cdot\left(-\sum_{j} \mathrm{D}_{i j} \nabla \rho_{i}\right)
$$

, but this has not been performed since except for very large residence times, both kinds of B.C. give similar results. Outlet boundary conditions were Neumann homogeneous (i.e. null-gradient) for all variables.

The preceding equations were discretized using a finite-volume technique, and the tridiagonal matrix resolution was performed with the help of the algorithm of Thomas [15]. Time integrations were performed with an implicit Newton-Raphson technique.

This transient solver was used for the mere determination of the steady-state behavior. Convergence is usually much slower in low-velocity situations, due to the increasing importance of backward diffusional effects. If Danckwerts B.C. were taken into account in such a case, then practical convergence times would not have been achieved.

\section{$2.2 \quad$ Kinetic mechanism}

Since hydrocarbon pyrolysis is a submechanism of combustion mechanism, numerous kinetic databases developed for the modeling of flames have been compiled for the constitution of our dataset.

Various steps may be distinguished during propane pyrolysis :

1. An initial homolytic decompositon of propane leading to light species such as methane and $\mathrm{C} 2$ up to $\mathrm{C} 4$ hydrocarbons ;

2. Various recombination steps between $\mathrm{C} 2, \mathrm{C} 3$ and $\mathrm{C} 4$ species leading to the first aromatic compounds, such as benzene, toluene, naphthalene, etc ...;

3. Formation of Polycyclic Aromatic Hydrocarbons (PAHs) by further addition or condensation mechanisms. 
For the first steps of propane decomposition, leading to small species (less than three carbon atoms), the databases of Tomlin [16], Dente and Ranzi [17], Tsang et al. $[18-22]$ and Baulch $[23,24]$ were used. For the formation of heavier species such as benzene and naphthalene, works on propane flames and soot formation of Marinov et al. [25], Westmoreland [26], Dean [27], Hidaka [28], Frenklach [29], Miller [30] and Côme et al. [31-34] were used.

The database has been built from all these sources following some rules : $i$ ) a sensitivity analysis has been performed on those constants for which scattered literature data are available, and the influence of this scattering has been checked. For example, reactions in partial quasi-equilibrium are very weakly influenced by the order of magnitude of the rate constant. Many reactions fell into this case. ii) it has been tried to keep data from the same author group for each submechanism, iii) in some tables (e.g. in [18-24]), uncertainty margins are given : if data from other sources do not agree with these margins, they are discarded, $i v)$ all reverse reaction data have been recomputed by our own means, and compared to the original data : in case of strong discrepancies, the original values have been discarded.

The reverse kinetic constants have been computed from thermodynamic considerations, since :

$$
\frac{k_{k}^{\text {forward }}}{k_{k}^{\text {reverse }}}=\left(\frac{P}{\mathcal{R} T}\right)^{\Delta_{k} \nu} \exp \left(-\frac{\Delta_{k} G^{\circ}(T)}{\mathcal{R} T}\right)
$$

The standard reaction enthalpies were computed from JANAF tables [35] and data from Barin et al. and Marinov [25], or from Benson's group contribution method [36-38] when no data were available.

The first reference mechanism (model A), including species up to naphthalene $\mathrm{C}_{10} \mathrm{H}_{8}$, has been studied and compared to experimental data. Then, two reduction methods have been applied to it [39] :

- the elimination of unimportant species, that is, species with both low algebraic production rates and relative concentrations,

- a principal component analysis allows to identify unimportant reactions which may be eliminated from the mechanism. 
A second model B has thus been obtained, with less than $1 \%$ error on the partial pressures of the molecular species compared to model $\mathrm{A}$ in the conditions considered here. This model has been finally completed by several steps involving species with higher molecular weights (up to phenanthrene $C_{14} H_{10}$ ), whose data were essentially taken from Marinov et al. [25], to obtain a third model referred to as model C.

Finally, mechanism D was set up by the addition of a simple Langmuir-Hinshelwood mechanism, as an attempt to represent the heterogeneous reactions. The kinetic parameters were obtained by a least-squares fitting of mass deposition rates with respect to the partial pressures of chosen species.

The whole setup strategy is summarized in table 1 . The homogeneous mechanisms $\mathrm{B} 2$ and $\mathrm{C}$ are summarized in appendix B.

Also, the normalized sensibility criterion of Turányi [39] has been computed for all species :

$$
B_{i}^{n}=\left(\frac{\partial \ln R_{n}}{\partial \ln c_{i}}\right)^{2}=\left(\frac{\partial R_{n}}{\partial c_{i}} \frac{c_{i}}{R_{n}}\right)^{2}
$$

This criterion indicates how species $i$ influences the production rates of species $n$. If a species $n$ is considered as important, then all species $i$ whose criteria $B_{i}^{n}$ are high should be retained. This method did not bring any reduction to model $\mathrm{C}$; however, modified criteria, obtained by splitting $B_{i}^{n}$ into two contributions linked respectively to the absolute production and consumption rates of $n$, have been used in order to identify submechanisms.

\section{Propane pyrolysis : results and discussion}

\subsection{Chemical model validation}

For the validation of the chemical mechanisms, partial pressures of main species at the outlet of the furnace where compared to experimental in-situ IR absorption data for two temperature set points (1073 $\mathrm{K}$ and $1273 \mathrm{~K}$ in a $0.1 \mathrm{~m}$ long hot zone). Various inflow velocities were used, leading to residence times ranging from 0.05 $s$ to $4 s$. Pure propane was used as precursor with a pressure of $2 \mathrm{kPa}$. Details 
of the experimental procedure and analysis results are given elsewhere [40]. The thermal profile was fitted with respect to experimental determinations. The furnace geometry is sketched in figure 1 .

The comparison between computations and experiments is only semi-quantitative, since only relative absorption data were available from FTIR measurements. It is known that the absorption peak areas of each species depend linearly on their concentration, but unfortunately the molar extinction coefficient is not known for every species. Moreover, if the species concentration is not constant all along the furnace length, the linearity is not verified any more. Fortunately, most molecular species are in constant concentration past the hot zone, that is, along most of the optical path. Comparing the partial pressures computed at the outlet of the furnace and the relative FTIR peak areas seems then to be sound enough for most molecular species.

The scales of the comparative plots in figure 2a) to h)) have been designed such that the curves obtained at $1073 K$ coincide at a residence time of $1 \mathrm{~s}$. No independent rescaling of the curves obtained at $1273 \mathrm{~K}$ has been made. These plots show the relatively good qualitative agreement between computations and FTIR data. It is even excellent for some species such as propane, acetylene, ethylene, butadiene, benzene, and naphthalene. Marked differences appear for methane at low residence times, as well as for allene and vinylacetylene at low temperatures, probably because one or several extra decomposition pathways were not taken into account. Despite such discrepancies, the fact that the agreement is good for relatively heavy species is an indication of the applicability of the model.

\subsection{Analysis of reaction fluxes}

In order to have a synthetic viewpoint over the mechanisms of propane pyrolysis, various synoptic schemes, based on the analysis of reaction fluxes, have been created (see figures 3-6). This allows to evidence the main reaction pathways for formation and decomposition of selected species of the kinetic model. 
These schemes have to be read in a similar way :

- The arrows denote the transformation of one species into another (not necessarily in a direct or unique way), and their thickness is proportional to the molar flux associated to the transformation ;

- The numbers in boldface characters correspond to the relative amounts of the molar (decomposition) fluxes starting from one species ;

- The numbers in italic characters denote the relative amount of the molar (production) fluxes leading to one species.

The whole model has been divided into four reaction groups summarized below :

1. First steps of propane decomposition, and C2 species ;

2. C3 species

3. C4 species

4. Aromatic compounds and PAH.

The "C3" and "C4" pathways for benzene and PAH formation have been much discussed by many authors. They rely on resonance-stabilized free radicals : propargyl $\mathrm{C}_{3} \mathrm{H}_{3}$ for the $\mathrm{C} 3$ pathway $[30,41,42]$, and $i \mathrm{C}_{4} H_{5}$ (1,3-butadien-2-yl) for the $\mathrm{C} 4$ pathway $[26,43-45]$. It will be tried to appreciate the relative importance of these reaction paths.

Similarly, the PAH formation has been explained with two different mechanisms :

- The HACA mechanism (Hydrogen Abstraction, $\mathrm{C}_{2} \mathrm{H}_{2}$ Addition) [29], which is an alternated succession of dehydrogenations and acetylene additions ;

- The RSFR mechanism (Resonance Stabilized Free Radicals) [25, 46, 47], involving the addition of radicals like propargyl $\mathrm{C}_{3} \mathrm{H}_{3}$, methylallenyl/1,3-butadienyl $\mathrm{C}_{4} \mathrm{H}_{5}$ and cyclopentadienyl $\mathrm{C}_{5} H_{5}$. 
We will also discuss the relative importance of these mechanisms in this studied case.

The analysis of the reaction fluxes has been performed at two reactor relative positions : $z=x / L=0.4$ (beginning of the hot zone, thereafter termed "cold zone") and $z=x / L=0.5$ (reactor center). This helps to understand the role of temperature and of the backward diffusion of the free radicals produced in the hottest zone.

\subsubsection{Propane decomposition}

Figure 3 shows that propane is decomposed by metathesis evenly into 1-propyl and 2-propyl radicals. The unimolecular decomposition into $\mathrm{C} 2+\mathrm{C} 1$, which is one of the initial steps of the whole mechanism, is minoritary. On the other hand, at high temperatures (i.e. at $z / L=0.5$ ), elimination of $\mathrm{H}_{2}$ with formation of propene dominates.

Ethylene originates itself essentially from two precursors : the propyl radical (predominantly at low temperatures), and the vinyl $\mathrm{C}_{2} H_{3}$ radical. Ethylene gives back the vinyl radical in a reversible way, which limits the formation of acetylene from this radical. In the hot zone, the equilibrium is displaced towards vinyl and acetylene formation ; however, this mechanism for vinyl formation is less important than the decomposition of propene. These facts are coherent with the experimental observation that propene appears sooner (lower $T$ and $t_{s}$ ) than ethylene.

The methyl radicals also are due to 1-propyl decomposition, and yield equally methane and ethane.

While at the beginning of the hot zone acetylene leads to the propenyl radical $v C_{3} H_{5}$, it rather participates to the formation of cyclic compounds $\left(\mathrm{C}_{6} \mathrm{H}_{6}, \mathrm{C}_{6} \mathrm{H}_{5}\right)$ and PAHs (through the HACA mechanism) at the reactor center.

\subsubsection{The C3 submechanism}

In this part of the mechanism (figure 4), the propargyl radical $C_{3} H_{3}$ plays a central role : it is indeed a key species for the formation of aromatic compounds. It 
originates itself from allene and propyne, themselves produced by two ways : one from propenyl, and the other from ethynyl $C_{2} H$. As seen before, the propenyl does not come from dehydrogenation of propene, but rather from methyl addition on acetylene. On the other hand, $C_{2} H$ does not come from the dehydrogenation of acetylene, but rather from the decomposition of $\mathrm{nC}_{4} \mathrm{H}_{3}$.

In the cold zone, the propenyl pathway is majoritary, but in the hot zone the $\mathrm{C}_{2} \mathrm{H}$ way predominates because of the larger amounts of $\mathrm{C} 4$ compounds production.

The C3 submechanism is limited to an equilibrium between $\mathrm{C}_{3} H_{3}$ and $\mathrm{C}_{3} \mathrm{H}_{4}$ in the cold zone, while in the hot zone, the production of benzene and $\mathrm{C}_{5} \mathrm{H}_{5}$ from $\mathrm{C}_{3} \mathrm{H}_{3}$ is active. This is in accordance with the experimental fact that C3 species appear for lower temperatures and residence times than $\mathrm{C} 4$ species.

\subsubsection{C4 compounds}

In this part (figure 5), the key species is the resonance stabilized $i C_{4} H_{5}$ radical, which is able to feed both the direct formation of benzene by addition on acetylene, and the formation of propargyl.

It originates principally from two sources : on one side, the dimerization of vinyl, and on another side the dehydrogenation of butadiene, itself produced by an addition of vinyl on ethylene.

It essentially decomposes into vinylacetylene $C_{4} H_{4}$, which is (mainly in the hot zone) a source of $\mathrm{C}_{2} \mathrm{H}$ radicals. In lesser amounts, it also leads to benzene by acetylene addition. Accordingly, it is deduced from these facts that benzene formation is owed principally to a $\mathrm{C} 4$ mechanism at low temperatures, but that the C3 pathway becomes non negligible at high temperatures.

\subsubsection{Formation of aromatic compounds}

As seen previously, benzene may be formed through two different pathways, but figure 6 shows that: $(i)$ the $\mathrm{C} 4$ way always dominates, and $(i i)$ benzene is not the only source for the PAHs. For instance, naphthalene is quite exclusively produced 
by the dimerization of cyclopentadienyl. Nevertheless, the HACA mechanism seems to be the main route to the formation of species with 3 or more cycles.

\subsubsection{Recapitulative diagrams}

To conclude with this mechanism description, fig. 7 summarizes the main pathways, either at low temperature and residence time, or at high values for these parameters, that is, at low and high maturation conditions.

\subsection{Conclusion}

The analysis of reaction fluxes has given a synthetic insight into the propane pyrolysis mechanism. The following issues have been identified :

- The propane and its direct subproducts $\left(1-\mathrm{C}_{3} H_{7}, 2-\mathrm{C}_{3} H_{7}, \mathrm{C}_{3} H_{6}\right)$ rapidly decompose into $\mathrm{C} 2$ species such as $\mathrm{C}_{2} \mathrm{H}_{4}$ and $\mathrm{C}_{2} \mathrm{H}_{2}$.

- In the hot zone, these $\mathrm{C} 2$ species themselves react, with formation of $\mathrm{C} 3-\mathrm{C} 4$ species by addition.

- The formation of C3 resonance stabilized radicals is not quicker than for C4 radicals, so that benzene formation is essentially owed to the latter.

- Naphthalene is not formed by the HACA mechanism, but the reverse is true for aromatic compounds with three or more cycles.

\section{Correlation with heterogeneous chemistry and pyrocarbon nanotexture}

Féron [6] and Lavenac [40] have determined deposition rates as a function of residence time in the same reactor that has been used for the FTIR study. Figure 8 gives typical results. Four domains may be distinguished : 
1. A domain at low residence times $\left(t_{s}<0,1 s\right)$, for which the deposition rate increases with residence time. The limiting phenomenon is the rate of homogeneous reactions.

2. A "plateau" for which the surface reactions limit the total deposition rate.

3. A third domain for which the deposition rate increases strongly with residence time. Again, homogeneous reactions are limiting.

4. A fourth domain with a decrease of the deposition rate, possibly due to mass transfer limitations.

It has also been found that smooth laminar (SL) pyrocarbon deposition coincides with the first two domains, rough laminar (RL) pyrocarbon deposition coincides with the third domain, and the fourth domain corresponds again to SL. These results, in addition with those of kinetic study and gas-phase analysis by FTIR, has led to the following qualitative mechanism [6]:

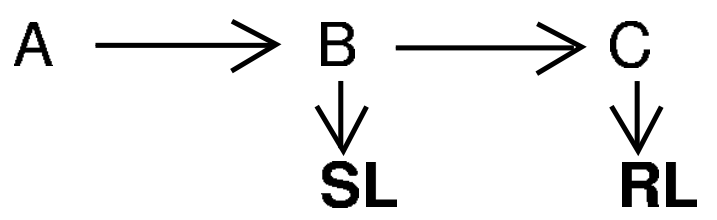

where $A$ is the initial precursor, $B$ stands for a group of light compounds and $C$ stands for a group of heavier hydrocarbons, which appear later during propane pyrolysis. It will be intended now to try to confirm such a mechanism with the help of the results of the former kinetic study.

\subsection{Hypotheses}

Since the reactor has a small surface-to-volume ratio, it may be considered in a first approximation that heterogeneous consumption reactions do not alter deeply the gas-phase concentrations of the reactants. This is the hypothesis of a weak coupling between homogeneous and heterogeneous chemistry. In such a framework, one may try to correlate directly the deposition rates and nanotextures to the previously computed gas-phase concentrations. The most frequently cited species as precursors for 
pyrocarbon or soot formation are acetylene, benzene, and the PAHs. Accordingly, we have selected the two former, plus naphthalene and phenanthrene, which are the first PAHs that are included in model C, for a comparison with deposition rates. Figure 9 is a plot of their scaled concentrations in the hot zone vs. residence time. Comparison with figure 8 suggests to split the selected species into two groups, the first one comprising acetylene, benzene and naphthalene, which display a very analogous behavior (even if naphthalene looks to appear for somewhat larger residence times), and the second one containing phenanthrene and whatever heavier species not taken explicitly into account in this model. The second group may be clearly related to the deposition of rough laminar pyrocarbon, and consequently the first one to smooth laminar pyrocarbon deposition.

The simplest attempt to build a quantitative model explaining pyrocarbon deposition would then be to select a species B from group 1 (e. g. benzene) and another species C from group 2 (phenanthrene and PAHs), and construct a double LangmuirHinshelwood mechanism :

$$
\begin{array}{rcccc} 
& k_{1} & & k_{2} & \\
B+* & \rightleftharpoons & B^{*} & \rightarrow & C_{S L}+x H_{2}+* \\
& k_{-1} & & & \\
& k_{3} & & k_{4} & \\
C+* & \rightleftharpoons & C^{*} & \rightarrow & C_{R L}+y H_{2}+* \\
& k_{-3} & & &
\end{array}
$$

where $*$ represents one surface adsorption site.

The kinetic law arising from such a mechanism is the following one :

$$
R=\frac{\frac{k_{2} k_{1}}{\left(k_{-1}+k_{2}\right)}[B]+\frac{k_{4} k_{3}}{\left(k_{-3}+k_{4}\right)}[C]}{1+\frac{k_{1}}{\left(k_{-1}+k_{2}\right)}[B]+\frac{k_{3}}{\left(k_{-3}+k_{4}\right)}[C]}=\frac{\alpha[B]+\beta[C]}{1+\gamma[B]+\delta[C]}
$$

It only relies on four parameters $\alpha, \beta, \gamma$ and $\delta . \gamma$ and $\delta$ are "Michælis-Menten"-like constants $\left(k_{\text {ads }} /\left(k_{\text {des }}+k_{r}\right)\right.$ (by analogy with classical enzyme kinetics), while $\alpha$ and $\beta$ are apparent deposition rate constants. 


\subsection{Results and discussion}

The tentative kinetic law 4.6 has been fitted to the experimental data, and an excellent agreement has been found for the deposition domains 2 and 3, as shown in figure 10. The exact values of the correlation parameters $\alpha, \beta, \gamma$, and $\delta$ are not of direct physical significance. However, some ratios allow to compare the two deposition mechanisms :

- The ratio $\gamma / \delta$ between the Michælian constants of $B$ and $C$ is very small : $K_{m}(B) / K_{m}(C) \approx 4 \cdot 10^{-4}$. This means that the relative amount of adsorbed molecules for group $B([B *] /[B])$ is much smaller than for group $C$. Three explanations for this are possible : $(i)$ the light species adsorb less efficiently than the heavy ones, (ii) they desorb more easily, and (iii) they react quicker when adsorbed. It is difficult to confirm one or another explanation since we do not have access to the adsorption constants $K_{a}=k_{a d s} / k_{\text {des }}$.

- The ratio $\alpha \delta / \beta \gamma=k_{2} / k_{4}$ is close to 0.5 , so that the group $C$ incorporation reaction is just a little faster than for group $B$.

The transition from smooth laminar to rough laminar may thus be explained : at low residence times, there is a negligible amount of group $C$ species, and the relatively slow mechanism yielding SL pyrocarbon dominates. The apparent order goes to zero when the surface sites are saturated with $B^{*}\left(R \rightarrow k_{2}\right.$ in equation 4.6$)$, and this explains the plateau in zone 2. Then, for a higher gas-phase maturation, the quicker RL deposition mechanism becomes predominant.

On the other hand, this model does not reproduce correctly the decrease of the deposition rate with residence time in the fourth zone $\left(t_{s}>2 s\right)$. This was already clear from the analytical expression 4.6 and the fact that the concentration of all selected species always increases. At most, one could expect from the model a new site saturation effect with a second plateau.

One should note that our model does not take into account the retroactive effect of heterogeneous kinetics on gas-phase concentrations. This effect is obviously more marked when the deposition rate increases, which is the case in zone 3. Consequently, 
the hypothesis of a transport limitation for zone 4 is not invalidated. Indeed, it has been computed that at $t_{s}=10 \mathrm{~s}$, the total molar deposition rate is about $10 \%$ of the total inlet carbon-equivalent mole rate. Taking into consideration that a large fraction of the gas is converted into poorly reactive species like $\mathrm{CH}_{4}$, one sees that the deposition rate is close to meet the effective reactant supply rate in such conditions.

Another explanation for the decrease in zone 4 would be the following one : as maturation increases, there is an increasing amount of PAHs with growing molecular weights, but if their size becomes too large, then their adsorption becomes more and more difficult, because of steric factors, so there would be a reactivity optimum for some critical PAH size.

The observed deposition rate in region 1 is not well reproduced either by this model, since the considered B-type species has non-zero concentration at very low residence times while the deposition rate is zero within experimental uncertainty. This could be explained by the fact that the deposition of SL pyrocarbon requires an extra intermediate that is not yet present at very low maturation conditions. Also, even the experimental data is questionable in this parameter region, because of deviations between the recorded thermocouple temperature and the effective bulk gas temperature : the apparent deposit rate is probably lower than expected.

\section{Conclusion}

In this work, a kinetic study for the pyrolysis of propane at 1100 and $1300 K$ and $2 \mathrm{kPa}$ has been performed. A numerical model has been set up, with a chemical mechanism including many light species and the first PAHs. It has been qualitatively validated with experimental FTIR data, and partially reduced. Two kinds of results have been obtained.

First, reaction pathways have been elucidated, at least partially. The main conclusions are : 
- The propane decomposes into $\mathrm{C} 2$ species according to two mechanisms : a slow initiation step, and a radical metathesis main step.

- The C4 submechanism is more important than the C3 submechanism for benzene formation in the considered conditions.

- Benzene is not the only key species for PAH formation, there is also for example naphthalene which is obtained through a C3 $\rightarrow$ C5 pathway.

- PAH growth occurs essentially through the HACA mechanism, except for some light aromatic compounds, such as naphthalene.

Second, a correlation has been carried out with deposition rate and nanotexture (SL/RL) repartition data. It has been found that the heaviest species included in the model (and probably yet heavier ones) are crucial for the deposition of the RL form of pyrocarbon. On the other hand, benzene and acetylene seem to be more related to the formation of SL pyrocarbon. This does not exclude that they also play a role in RL formation.

The reduction of the homogeneous mechanism has been only partially carried out, since it was already enough for a 1D solver ; it should be pushed forward by the application of more sophisticated methods, like QSSA [39], ILDM [48] or repromodelling [49], in order to use it in a 2D solver for CVI problems [50] - this is the aim of future work.

Also, more precise models should be seeked for the heterogeneous chemistry part, as previously done for diamond deposition [51], but a serious drawback is the almost complete lack of information about the structure of pyrocarbon surfaces : site abundances, defect distributions, etc...

\section{Acknowledgements}

The authors wish to acknowledge the support of CNRS and SNECMA through a BDI-E CNRS/SNECMA grant to C. D..

Useful discussions and data exchange with R. Fournet and G.-M. Côme (DCPRENSIC Nancy), and E. Sion (Messier-Bugatti/Carbone Industrie) have helped us 
along our work. 


\section{References}

[1] F. Christin, R. Naslain, and C. Bernard, in Proc. 7th International Conference on CVD, T. O. Sedgwick and H. Lydtin, Editors, PV 79-3,p. 499, The Electrochemical Society Proceedings Series, Pennington, NJ (1979).

[2] R. Naslain, J. Y. Rossignol, P. Hagenmuller, F. Christin, L. Héraud, and J. J. Choury, Rev. de Chim. Min., 18, 544 (1981).

[3] J. D. Buckley, in Proc. $9^{\text {th }}$ Intl. Conf. on Composite Mater. (ICCM-9), A. Miravete, Editor, vol. 3, p. 675, Woodhead, Cambridge, UK (1993).

[4] P. Loll, PhD thesis, Université Bordeaux 1 n 240 (1976).

[5] P. Loll, P. Delhaès, A. Pacault, and A. Pierre, Carbon, 15, 383 (1977).

[6] O. Féron, PhD thesis, Université Bordeaux 1 nº 1867 (1998).

[7] P. Lieberman and O. Pierson, Carbon, 12, 233 (1974).

[8] H. O. Pierson and M. L. Lieberman, Carbon, 13, 159 (1975).

[9] P. McAllister and E. E. Wolf, AICHE J., 39, 1196 (1993).

[10] P. Dupel, R. Pailler, and F. Langlais, J. Mater. Sci., 29, 1341 (1994).

[11] O. Féron, F. Langlais, R. Naslain, and J. Thébault Carbon, 37, 1343 (1999).

[12] E. P. Bartlett, R. M. Kendall, and R. Rindal, Technical Report 66-7, NASA (1968).

[13] V. Giovangigli, Impact of Computing in Science and Engineering, 2, 73 (1990).

[14] O. Levenspiel, Chemical reaction engineering, John Wiley \& sons, New York (1972).

[15] W. H. Press, S. A. Teukolsy, W. T. Vetterling, and B. P. Flannery, Numerical recipes in FORTRAN. The art of scientific computing, Cambridge University Press, New York (1992). 
[16] A. S. Tomlin, M. J. Pilling, J. H. Merckin, J. Brindley, N. Burgess, and A. Gough, Ind. Eng. Chem. Res., 34, 3749 (1995).

[17] M. E. Dente and E. M. Ranzi, in Pyrolysis: Theory and industrial practice, Lyle F. Albright, Billy L. Cranes, and William H. Corcoran, Editors, p. 133, Academic press Inc., New York (1983).

[18] W. Tsang, Ind. Eng. Chem. Res., 31, 3 (1992).

[19] W. Tsang and R. F. Hampson, J. Phys. Chem. Ref. Data, 15, 1087 (1986).

[20] W. Tsang, J. Phys. Chem. Ref. Data, 16, 471 (1987).

[21] W. Tsang, J. Phys. Chem. Ref. Data, 17, 887 (1988).

[22] W. Tsang, J. Phys. Chem. Ref. Data, 20, 221 (1991).

[23] D. L. Baulch, C. J. Cobos, R. A. Cox, C. Esser, P. Frank, Th. Just, J. A. Kerr, M. J. Pilling, J. Troe, R. W. Walker, and J. Warnatz, J. Phys. Chem. Ref. Data, 21, 411 (1992).

[24] D. L. Baulch, C. J. Cobos, R. A. Cox, , P. Frank, G. Hayman, Th. Just, J. A. Kerr, T. Murrels, M. J. Pilling, J. Troe, R. W. Walker, and J. Warnatz, Combustion and flame, 98, 59 (1994).

[25] N. M. Marinov, W. J. Pitz, C. K. Westbrook, M. J. Castaldi, and S. M. Senkan, Combust. Sci. and Tech., 116-117, 211 (1996).

[26] P. R. Westmoreland and J. B. Howard, in 21st (Intl.) Symposium on Combustion, page 773, The Combustion Institute, Pittsburgh, PA (1986).

[27] A. M. Dean, J. Phys. Chem., 89, 4600 (1985).

[28] Y. Hidaka, K. Hattori, T. Okuno, K. Inami, T. Abe, and T. Koike, Combustion and Flame, 107, 401 (1996).

[29] M. Frenklach and J. Warnatz, Combust. Sci. and Tech., 51, 265 (1987).

[30] J. A. Miller and C. F. Melius, Combustion and Flame, 91, 21 (1992). 
[31] P. Barbé, F. Battin-Leclerc, and G.-M. Côme, J. Chem. Phys., 92, 1666 (1995).

[32] G.-M. Côme, V. F. Warth, P. A. Glaude, R. Fournet, F. Battin-Leclerc, and G. Scacchi, in Proc. $26^{\text {th }}$ Intl. Symposium on Combustion, A. R. Burgess, F. L. Dryer, and N. Peters, Editors, p. 1289, The Combustion Institute, Pittsburgh, PA (1996).

[33] R. Fournet, Personal Communication (1996).

[34] R. Fournet, J.-C. Baugé, and F. Battin-Leclerc, Int. J. Chem. Kinetics, 31, 361 (1996).

[35] M. W. Chase Jr., C. A. Davies, J. R. Downey Jr., D. J. Frurip, R. A. McDonald, and A. N. Syverud, editors. JANAF Thermochemical Tables, vol 14 of J. Phys. Chem. Ref. Data. $3^{\text {rd }}$ ed., American Chemical Society, Washington, DC (1985).

[36] S. W. Benson, Thermochemical kinetics, $2^{\text {nd }}$ ed., John Wiley \& Sons, New York, (1976).

[37] S. W. Benson, F. R. Cruickshank, D. M. Golden, G. R. Haugen, H. E. O’Neal, A. S. Rodgers, R. Shaw, and R. Walsh, Chem. Rev., 69, 279 (1968).

[38] G.-M. Côme. Réactions chimiques en phase gazeuse. Thermodynamique, cinétique, mécanismes réactionnels, $1^{\text {st }}$ ed., Ellipses, Paris, France (1999).

[39] T. Turányi, New J. Chem., 14, 795 (1990).

[40] J. Lavenac, PhD thesis, Université Bordeaux 1 nº 2274 (2000).

[41] C. H. Wu and R. D. Kern, J. Phys. Chem., 91, 6291 (1987).

[42] S. Senkan and M. Castaldi, Combustion and Flame, 107 ,141 (1996).

[43] J. A. Cole, J. D. Bitnner, J. P. Longwell, and J. B. Howard, Combustion and Flame, 56, 51 (1984).

[44] F. C. Stehling, J. D. Frazee, and R. C. Anderson, in Proc. Sixth Symposium on Combustion, p. 247, The Combustion Institute, Pittsburgh, PA (1956). 
[45] M. Frenklach,in $26^{\text {th }}$ Symp. (Intl.) on Combustion, A. R. Burgess, F. L. Dryer, and N. Peters, Editors, p. 2285, The Combustion Institute, Pittsburgh, PA (1996).

[46] C. F. Melius, M. E. Coltrin, N. M. Marinov, W. J. Pitz, and S. M. Senkan, in $26^{\text {th }}$ Symp. (Intl.) on Combustion, A. R. Burgess, F. L. Dryer, and N. Peters, Editors, p. 685, The Combustion Institute, Pittsburgh, PA (1996).

[47] J. L. Emdee, K. Brezinsinky, and I. Glassman, in 23rd Symp. (Int.) on Combustion, p. 77, The Combustion Institute, Pittsburgh, PA (1990).

[48] T. Blasenbrey, D. Schmidt, and U. Maas, in Proc. Workshop on numerical aspects of reduction in chemical kinetics, A. Ern and B. Sportisse, Editors, CERMICS, Champs sur Marne, France (1997).

[49] T. Turányi, in Proc. Workshop on numerical aspects of reduction in chemical kinetics, A. Ern and B. Sportisse, Editors, CERMICS, Champs sur Marne, France (1997).

[50] G. L. Vignoles, C. Descamps, and N. Reuge. Interaction between a reactive preform and the surrounding gas-phase during CVI, in Euro-CVD 12 Proceedings, A. Figueras, editor, vol. 10 of J. de Phys. IV , p. Pr2-9, EDP Sciences, Les Ulis, France (2000).

[51] M. Okkerse, M.H.J.M. de Croon, C. R. Kleijn, H. E. A. van den Akker, and G. B. Marin, J. Appl. Phys., 84, 6387 (1998). 


\section{A List of symbols}

\section{A.1 Latin}

$B_{i}^{n} \quad$ Normalized sensitivity criterion of reaction $n$ with respect to species $i(-)$

$c_{i} \quad$ Concentration of species $i\left(\mathrm{~mol} . \mathrm{m}^{-3}\right)$

$\mathrm{D}_{i j} \quad$ Multicomponent diffusion coefficient of species $i$ vs. species $j\left(m^{2} . s^{-1}\right)$

$G^{\circ} \quad$ Molar free enthalpy at $P=1 \mathrm{~atm}\left({\left.\mathrm{~J} . \mathrm{mol}^{-1}\right)}^{-1}\right.$

$k \quad$ Reaction constant $\left(\left(\text { mol. } m^{-3}\right)^{(1-\text { order })} \cdot s^{-1}\right)$

$M_{i} \quad$ Molar mass of species $i\left(\mathrm{~kg}_{\mathrm{mol}} \mathrm{mol}^{-1}\right)$

$P \quad$ Total pressure $(P a)$

$\mathcal{R}$ Perfect gas constant $\left(J . \mathrm{mol}^{-1} \cdot K^{-1}\right)$

$R_{i} \quad$ Production rate for species $i\left(\mathrm{~mol} . \mathrm{m}^{-3} . \mathrm{s}^{-1}\right)$

$T$ Temperature $(K)$

$t \quad$ Time $(s)$

$t_{s} \quad$ Residence time in the hot zone $(s)$

v Fluid barycentric velocity $\left(m . s^{-1}\right)$

$z \quad$ Relative position in the tubular furnace (-)

\section{A.2 Greek}

$\alpha, \beta, \gamma, \delta \quad$ Fitting coefficients in relation 4.6

$\Delta_{k} \bullet \quad$ Difference operator between products and reactants for reaction $k$

$\rho \quad$ Volumic mass $\left(k g \cdot m^{-3}\right)$

$\rho_{i} \quad$ Partial volumic mass of species $i\left(\mathrm{~kg} \cdot \mathrm{m}^{-3}\right)$

$\nu_{i k} \quad$ Stoichiometric coefficient of species $i$ in reaction $k(-)$ 


\section{B Reduced mechanism with 53 species and 205 reactions}

This appendix summarizes the chemical reactions of the reduced model B2 leading to benzene and naphthalene, plus the added routes to heavier molecules up to phenanthrene (mechanism $\mathrm{C}$ ). For each reaction, the kinetic parameters are in accordance with the Arrhenius-Kooij formalism :

$$
k=A T^{\beta} \exp \left(\frac{E_{a}}{\mathcal{R} T}\right)
$$

All quantities are in S. I. units $(m, s, J, m o l)$. For the reactions involving a pressuredependent "fall-off" regime, the parameter values in the low-pressure limit are given between parentheses. 
Reactions of propane $C_{3} H_{8}$

\begin{tabular}{|c|c|c|c|}
\hline Reaction & $A$ & $E_{a}$ & $\beta$ \\
\hline $\mathrm{C}_{3} \mathrm{H}_{8}+\mathrm{H} \rightarrow \mathrm{H}_{2}+1-\mathrm{C}_{3} H_{7}$ & $1.33 \mathrm{e} 0$ & 28215 & 2.54 \\
\hline $\mathrm{C}_{3} \mathrm{H}_{8}+\mathrm{H} \rightarrow \mathrm{H}_{2}+2-\mathrm{C}_{3} \mathrm{H}_{7}$ & $1.30 \mathrm{e} 0$ & 18685 & 2.40 \\
\hline $\mathrm{C}_{3} \mathrm{H}_{8}+\mathrm{CH}_{3} \rightarrow \mathrm{CH}_{4}+1-\mathrm{C}_{3} \mathrm{H}_{7}$ & $0.9 \mathrm{e}-6$ & 29887 & 3.65 \\
\hline $\mathrm{C}_{3} \mathrm{H}_{8}+\mathrm{CH}_{3} \rightarrow \mathrm{CH}_{4}+2-\mathrm{C}_{3} \mathrm{H}_{7}$ & $1.5 \mathrm{e}-6$ & 22906 & 3.46 \\
\hline$C_{3} H_{8}+C_{2} H_{3} \rightarrow C_{2} H_{4}+1-C_{3} H_{7}$ & $6.0 \mathrm{e}-4$ & 43890 & 3.3 \\
\hline $\mathrm{C}_{3} \mathrm{H}_{8}+\mathrm{C}_{2} \mathrm{H}_{3} \rightarrow \mathrm{C}_{2} \mathrm{H}_{4}+2-\mathrm{C}_{3} \mathrm{H}_{7}$ & $1.0 \mathrm{e}-3$ & 43890 & 3.3 \\
\hline $\mathrm{C}_{3} \mathrm{H}_{8}+\mathrm{C}_{2} \mathrm{H}_{5} \rightarrow \mathrm{C}_{2} \mathrm{H}_{6}+1-\mathrm{C}_{3} \mathrm{H}_{7}$ & $0.9 \mathrm{e}-6$ & 38205 & 3.65 \\
\hline $\mathrm{C}_{3} \mathrm{H}_{8}+\mathrm{C}_{2} \mathrm{H}_{5} \rightarrow \mathrm{C}_{2} \mathrm{H}_{6}+2-\mathrm{C}_{3} \mathrm{H}_{7}$ & $1.21 \mathrm{e}-6$ & 31224 & 3.46 \\
\hline$C_{3} H_{8}+a C_{3} H_{5} \rightarrow C_{3} H_{6}+1-C_{3} H_{7}$ & $2.5 \mathrm{e} 7$ & 98230 & 0 \\
\hline$C_{3} H_{8}+v C_{3} H_{5} \rightarrow C_{3} H_{6}+1-C_{3} H_{7}$ & $7.9 \mathrm{e} 6$ & 32604 & 0 \\
\hline$C_{3} H_{8}+v C_{3} H_{5} \rightarrow C_{3} H_{6}+2-C_{3} H_{7}$ & $2.5 \mathrm{e} 6$ & 32604 & 0 \\
\hline $\mathrm{C}_{3} \mathrm{H}_{8}+\mathrm{CyC}_{5} \mathrm{H}_{5} \rightarrow \mathrm{CyC}_{5} \mathrm{H}_{6}+1-\mathrm{C}_{3} \mathrm{H}_{7}$ & $2.51 \mathrm{e} 7$ & 135850 & 0 \\
\hline$C_{3} H_{8}+C y C_{5} H_{5} \rightarrow C y C_{5} H_{6}+2-C_{3} H_{7}$ & $7.94 \mathrm{e} 6$ & 135850 & 0 \\
\hline $2-\mathrm{C}_{3} \mathrm{H}_{7} \rightarrow 1-\mathrm{C}_{3} \mathrm{H}_{7}$ & $1.0 \mathrm{e} 13$ & 158840 & 0 \\
\hline $1-C_{3} H_{7} \rightarrow 2-C_{3} H_{7}$ & $2.5 \mathrm{e} 12$ & 142120 & 0 \\
\hline $\mathrm{C}_{3} \mathrm{H}_{8} \rightarrow \mathrm{C}_{3} \mathrm{H}_{6}+\mathrm{H}_{2}$ & $5.01 \mathrm{e} 13$ & 292600 & 0 \\
\hline \multirow[t]{2}{*}{$C_{3} H_{8}(+M) \rightarrow C_{2} H_{5}+C_{3}(+M)$} & $7.9 \mathrm{e} 22$ & $3.71 \mathrm{e} 5$ & -1.8 \\
\hline & $(7.8 \mathrm{e} 12)$ & $(2.72 \mathrm{e} 5)$ & $(0)$ \\
\hline
\end{tabular}


Reactions of ethylene $\mathrm{C}_{2} \mathrm{H}_{4}$

\begin{tabular}{llll}
\hline Reaction & $A$ & $E_{a}$ & $\beta$ \\
\hline$C_{2} H_{4}+H \rightarrow C_{2} H_{3}+H_{2}$ & $1.3 \mathrm{e} 0$ & 50996 & 2.53 \\
$C H_{3}+C_{2} H_{4} \rightarrow C_{4}+C_{2} H_{3}$ & $3.3 \mathrm{e}-6$ & 39710 & 3.7 \\
$C_{2} H_{4}+C H_{3} \rightarrow C_{3} H_{6}+H$ & $6.6 \mathrm{e} 5$ & 66462 & 0 \\
$C_{2} H_{4}+C_{2} H_{3} \rightarrow C_{4} H_{6}+H$ & $5.0 \mathrm{e} 5$ & 31350 & 0 \\
$C_{2} H_{4}+C_{2} H_{3} \rightarrow 4-C_{4} H_{7}$ & $3.98 \mathrm{e} 5$ & 25080 & 0 \\
$4-C_{4} H_{7} \rightarrow C_{2} H_{4}+C_{2} H_{3}$ & $1.995 \mathrm{e} 14$ & 165110 & 0 \\
$C_{2} H_{4}+2-C_{3} H_{7} \rightarrow C_{3} H_{8}+C_{2} H_{3}$ & $5.6 \mathrm{e}-9$ & 33440 & 4.2 \\
$C_{2} H_{4}+2-C_{3} H_{7} \rightarrow C_{3} H_{6}+C_{2} H_{5}$ & $2.65 \mathrm{e} 4$ & 27588 & 0 \\
$C_{2} H_{4}+C_{2} H \rightarrow C_{4} H_{4}+H$ & $1.2 \mathrm{e} 7$ & 0 & 0 \\
$C_{2} H_{5}+2-C_{3} H_{7} \rightarrow C_{3} H_{8}+C_{2} H_{4}$ & $1.8 \mathrm{e} 7$ & 0 & -0.3 \\
$1-C_{3} H_{7} \rightarrow H_{3}+C_{2} H_{4}$ & $2.0 \mathrm{e} 13$ & 129580 & 0 \\
$C_{3}+C_{2} H_{4} \rightarrow 1-C_{3} H_{7}$ & 21.40 & 33865 & 1.34 \\
$C_{2} H_{5}(+M) \rightarrow C_{2} H_{4}+H(+M)$ & $8.2 \mathrm{e} 13$ & $1.67 \mathrm{e} 5$ & 0 \\
$C_{2} H_{4}+H(+M) \rightarrow C_{2} H_{5}(+M)$ & $(3.4 \mathrm{e} 11)$ & $(1.397 \mathrm{e} 5)$ & $(0)$ \\
& $3.97 \mathrm{e} 3$ & $5.44 \mathrm{e} 3$ & 1.28 \\
\hline
\end{tabular}

Reactions of methane $\mathrm{CH}_{4}$

\begin{tabular}{|c|c|c|c|}
\hline Reaction & $A$ & $E_{a}$ & $\beta$ \\
\hline $\mathrm{CH}_{4}+\mathrm{H} \rightarrow \mathrm{CH}_{3}+\mathrm{H}_{2}$ & $1.3 \mathrm{e}-2$ & 33440 & 3.0 \\
\hline $\mathrm{CH}_{4}+\mathrm{C}_{2} \mathrm{H}_{3} \rightarrow \mathrm{CH}_{3}+\mathrm{C}_{2} \mathrm{H}_{4}$ & $5.01 \mathrm{e} 6$ & 32604 & 0 \\
\hline $\mathrm{CH}_{4}+\mathrm{C}_{2} \mathrm{H}_{5} \rightarrow \mathrm{C}_{2} \mathrm{H}_{6}+\mathrm{CH}_{3}$ & $1.86 \mathrm{e}-15$ & 38550 & 6.52 \\
\hline $\mathrm{CH}_{4}+v \mathrm{C}_{3} \mathrm{H}_{5} \rightarrow \mathrm{C}_{3} \mathrm{H}_{6}+\mathrm{CH}_{3}$ & $7.8 \mathrm{e} 16$ & 41230 & -3.22 \\
\hline $\mathrm{CH}_{4}+n \mathrm{C}_{4} \mathrm{H}_{3} \rightarrow \mathrm{C}_{4} \mathrm{H}_{4}+\mathrm{CH}_{3}$ & $1.73 \mathrm{e} 6$ & 54612 & 0.61 \\
\hline $\mathrm{CH}_{4}+\mathrm{CyC}_{5} \mathrm{H}_{5} \rightarrow \mathrm{CyC}_{5} \mathrm{H}_{6}+\mathrm{CH}_{3}$ & $1.58 \mathrm{e} 7$ & 135850 & 0 \\
\hline $\mathrm{CH}_{3}+\mathrm{CH}_{3} \rightarrow \mathrm{C}_{2} \mathrm{H}_{5}+\mathrm{H}$ & $3.0 \mathrm{e} 7$ & 56430 & 0 \\
\hline \multirow[t]{2}{*}{$\mathrm{CH}_{4}(+\mathrm{M}) \rightarrow \mathrm{CH}_{3}+\mathrm{H}(+\mathrm{M})$} & $2.4 \mathrm{e} 16$ & 440154 & 0 \\
\hline & $(1.29 \mathrm{e} 12)$ & $(1.59 \mathrm{e} 3)$ & $(0)$ \\
\hline
\end{tabular}


Reactions of propene $C_{3} H_{6}$

\begin{tabular}{|c|c|c|c|}
\hline Reaction & $A$ & $E_{a}$ & $\beta$ \\
\hline $\mathrm{C}_{3} \mathrm{H}_{6} \rightarrow \mathrm{C}_{2} \mathrm{H}_{3}+\mathrm{CH}_{3}$ & $1.2 \mathrm{e} 21$ & 408474 & 1.2 \\
\hline $\mathrm{C}_{2} \mathrm{H}_{3}+\mathrm{CH}_{3} \rightarrow \mathrm{C}_{3} \mathrm{H}_{6}$ & $2.5 \mathrm{e} 7$ & 0 & 0 \\
\hline $1-C_{3} H_{7} \rightarrow C_{3} H_{6}+H$ & $3.0 \mathrm{e} 13$ & 158840 & 0 \\
\hline $2-C_{3} H_{7}+2-C_{3} H_{7} \rightarrow C_{3} H_{6}+C_{3} H_{8}$ & $2.4 \mathrm{e} 6$ & 0 & 0 \\
\hline$a C_{3} H_{5}+H \rightarrow C_{3} H_{6}$ & $1.7 \mathrm{e} 8$ & 0 & 0 \\
\hline$v C_{3} H_{5} \rightarrow a C_{3} H_{5}$ & $5.0 \mathrm{e} 13$ & 154660 & 0 \\
\hline$a C_{3} H_{5} \rightarrow v C_{3} H_{5}$ & $3.47 \mathrm{e} 16$ & $2.58 \mathrm{e} 5$ & -0.685 \\
\hline \multicolumn{4}{|l|}{ Reactions of dihydrogen $\mathrm{H}_{2}$} \\
\hline Reaction & $A$ & $E_{a}$ & $\beta$ \\
\hline $\mathrm{H}_{2}+\mathrm{CH}_{3} \rightarrow \mathrm{CH}_{4}+\mathrm{H}$ & $6.0 \mathrm{e}-3$ & 39292 & 2.7 \\
\hline $\mathrm{H}_{2}+\mathrm{C}_{2} \mathrm{H}_{3} \rightarrow \mathrm{H}+\mathrm{C}_{2} \mathrm{H}_{4}$ & $1.26 \mathrm{e} 6$ & 32604 & 0 \\
\hline $\mathrm{H}_{2}+\mathrm{C}_{2} \mathrm{H}_{5} \rightarrow \mathrm{C}_{2} \mathrm{H}_{6}+\mathrm{H}$ & $4.49 \mathrm{e}-2$ & 40167 & 2.33 \\
\hline$H_{2}+2-C_{3} H_{7} \rightarrow H+C_{3} H_{8}$ & $1.55 \mathrm{e}-5$ & 31853 & 3.46 \\
\hline$H_{2}+C_{3} H_{3} \rightarrow p C_{3} H_{4}+H$ & $4.53 \mathrm{e}-5$ & 66235 & 3.16 \\
\hline$H_{2}+C_{3} H_{3} \rightarrow a C_{3} H_{4}+H$ & 70.0 & 68272 & 0.77 \\
\hline$H_{2}+n C_{4} H_{3} \rightarrow C_{4} H_{4}+H$ & $2.8 \mathrm{e} 6$ & 46816 & 0 \\
\hline$H_{2}+i C_{4} H_{3} \rightarrow C_{4} H_{4}+H$ & $4.2 \mathrm{e} 6$ & 91542 & 0 \\
\hline $\mathrm{H}_{2}+i \mathrm{C}_{4} \mathrm{H}_{3} \rightarrow \mathrm{C}_{2} \mathrm{H}_{2}+\mathrm{C}_{2} \mathrm{H}_{3}$ & $5.0 \mathrm{e} 4$ & 83600 & 0 \\
\hline $\mathrm{H}_{2}+\mathrm{C}_{6} \mathrm{H}_{4} \mathrm{C}_{2} \mathrm{H} \rightarrow \mathrm{C}_{6} \mathrm{H}_{5} \mathrm{C}_{2} \mathrm{H}+\mathrm{H}$ & $1.65 \mathrm{e}-2$ & 34047 & 0.85 \\
\hline $\mathrm{H}_{2}+\mathrm{C}_{6} \mathrm{H}_{5} \mathrm{CH}_{2} \rightarrow \mathrm{C}_{6} \mathrm{H}_{5} \mathrm{CH}_{3}+\mathrm{H}$ & $7.04 \mathrm{e} 0$ & 57037 & 3.58 \\
\hline
\end{tabular}


Reactions of ethane $C_{2} H_{6}$

\begin{tabular}{|c|c|c|c|}
\hline Reaction & $A$ & $E_{a}$ & $\beta$ \\
\hline $\mathrm{C}_{2} \mathrm{H}_{6}+\mathrm{H} \rightarrow \mathrm{C}_{2} \mathrm{H}_{5}+\mathrm{H}_{2}$ & $1.4 \mathrm{e} 3$ & 30932 & 1.5 \\
\hline $\mathrm{C}_{2} \mathrm{H}_{6}+\mathrm{CH}_{3} \rightarrow \mathrm{C}_{2} \mathrm{H}_{5}+\mathrm{CH}_{4}$ & $1.5 \mathrm{e}-13$ & 24244 & 6.0 \\
\hline $\mathrm{C}_{2} \mathrm{H}_{6}+\mathrm{C}_{2} \mathrm{H}_{3} \rightarrow \mathrm{C}_{2} \mathrm{H}_{5}+\mathrm{C}_{2} \mathrm{H}_{4}$ & $6.0 \mathrm{e}-4$ & 43890 & 3.3 \\
\hline \multirow[t]{2}{*}{$\mathrm{C}_{2} \mathrm{H}_{6}(+\mathrm{M}) \rightarrow \mathrm{CH}_{3}+\mathrm{CH}_{3}(+\mathrm{M})$} & $3.16 \mathrm{e} 23$ & $3.84 \mathrm{e} 5$ & -1.86 \\
\hline & $(9.80 \mathrm{e} 44)$ & $(3.97 \mathrm{e} 5)$ & $(-8.84)$ \\
\hline \multirow{2}{*}{$\mathrm{CH}_{3}+\mathrm{CH}_{3}(+\mathrm{M}) \rightarrow \mathrm{C}_{2} \mathrm{H}_{6}(+M)$} & $3.6 \mathrm{e} 7$ & 0 & 0 \\
\hline & $(1.3 \mathrm{e} 29)$ & $(1.25 \mathrm{e} 4)$ & $(-7.0)$ \\
\hline \multicolumn{4}{|l|}{ Reactions of acetylene $\mathrm{C}_{2} \mathrm{H}_{2}$} \\
\hline Reaction & $A$ & $E_{a}$ & $\beta$ \\
\hline $\mathrm{C}_{2} \mathrm{H}_{3}+\mathrm{C}_{2} \mathrm{H}_{2} \rightarrow n \mathrm{C}_{4} \mathrm{H}_{5}$ & $1.0 \mathrm{e} 6$ & 22990 & 0 \\
\hline$n \mathrm{C}_{4} \mathrm{H}_{5} \rightarrow \mathrm{C}_{2} \mathrm{H}_{3}+\mathrm{C}_{2} \mathrm{H}_{2}$ & $2.0 \mathrm{e} 13$ & 119966 & 0 \\
\hline $\mathrm{CH}_{3}+\mathrm{C}_{2} \mathrm{H}_{2} \rightarrow v \mathrm{C}_{3} \mathrm{H}_{5}$ & $2.0 \mathrm{e} 6$ & 38038 & 0 \\
\hline$v \mathrm{C}_{3} \mathrm{H}_{5} \rightarrow \mathrm{CH}_{3}+\mathrm{C}_{2} \mathrm{H}_{2}$ & $2.0 \mathrm{e} 13$ & 129580 & 0 \\
\hline $\mathrm{C}_{2} \mathrm{H}_{2}+\mathrm{nC}_{4} \mathrm{H}_{3} \rightarrow \mathrm{C}_{6} \mathrm{H}_{5}$ & $3.33 \mathrm{e} 18$ & 38498 & -3.89 \\
\hline $\mathrm{C}_{2} \mathrm{H}_{2}+2-\mathrm{C}_{3} \mathrm{H}_{7} \rightarrow \mathrm{CH}_{3}+\mathrm{C}_{4} \mathrm{H}_{6}$ & $2.77 \mathrm{e} 4$ & 27170 & 0 \\
\hline $\mathrm{C}_{2} \mathrm{H}_{2}+a C_{3} H_{5} \rightarrow C y C_{5} H_{6}+H$ & $1.99 \mathrm{e} 5$ & 54340 & 0 \\
\hline $\mathrm{C}_{2} \mathrm{H}_{2}+\mathrm{CH}_{3} \rightarrow \mathrm{C}_{2} \mathrm{H}+\mathrm{CH}_{4}$ & $6.92 \mathrm{e} 5$ & 86612 & 0.12 \\
\hline $\mathrm{C}_{2} \mathrm{H}_{2}+\mathrm{C}_{2} \mathrm{H} \rightarrow n \mathrm{C}_{4} \mathrm{H}_{3}$ & $1.0 \mathrm{e} 6$ & -1508 & 0.5 \\
\hline$n \mathrm{C}_{4} \mathrm{H}_{3} \rightarrow \mathrm{C}_{2} \mathrm{H}_{2}+\mathrm{C}_{2} \mathrm{H}$ & $6.45 \mathrm{e} 17$ & $2.2 \mathrm{e} 5$ & -0.59 \\
\hline $\mathrm{C}_{2} \mathrm{H}_{2}+\mathrm{C}_{2} \mathrm{H} \rightarrow \mathrm{C}_{4} \mathrm{H}_{2}+\mathrm{H}$ & $4.0 \mathrm{e} 7$ & 0 & 0 \\
\hline \multirow[t]{2}{*}{$C_{2} H_{2}+H(+M) \rightarrow C_{2} H_{3}(+M)$} & $8.43 \mathrm{e} 6$ & $1.07 \mathrm{e} 4$ & 0 \\
\hline & $(3.43 \mathrm{e} 6)$ & $(6.15)$ & $(0)$ \\
\hline \multirow[t]{2}{*}{$C_{2} H_{3}(+M) \rightarrow C_{2} H_{2}+H(+M)$} & $1 \mathrm{e} 14$ & $1.66 \mathrm{e} 5$ & 0 \\
\hline & $(6.00 \mathrm{e} 35)$ & $(190399)$ & $(-7.5)$ \\
\hline
\end{tabular}


Reactions of 1,3-butadiene $C_{4} H_{6}$

\begin{tabular}{|c|c|c|c|}
\hline Reaction & $A$ & $E_{a}$ & $\beta$ \\
\hline $\mathrm{C}_{4} \mathrm{H}_{6}+\mathrm{CH}_{3} \rightarrow n \mathrm{C}_{4} \mathrm{H}_{5}+\mathrm{CH}_{4}$ & $7.0 \mathrm{e} 7$ & 77330 & 0 \\
\hline $\mathrm{C}_{4} \mathrm{H}_{6}+\mathrm{C}_{2} \mathrm{H}_{2} \rightarrow \mathrm{CyC}_{6} \mathrm{H}_{8}$ & $2.3 \mathrm{e} 6$ & $1.46 \mathrm{e} 5$ & 0 \\
\hline $\mathrm{CyC}_{6} \mathrm{H}_{8} \rightarrow \mathrm{C}_{4} \mathrm{H}_{6}+\mathrm{C}_{2} \mathrm{H}_{2}$ & $1.49 \mathrm{e} 25$ & $3.835 \mathrm{e} 5$ & -2.56 \\
\hline $\mathrm{C}_{4} \mathrm{H}_{6}+\mathrm{C}_{2} \mathrm{H}_{3} \rightarrow \mathrm{CyC}_{6} \mathrm{H}_{8}+\mathrm{H}$ & $2.28 \mathrm{e} 6$ & 41466 & -0.24 \\
\hline $\mathrm{C}_{4} \mathrm{H}_{6}+\mathrm{H} \rightarrow a \mathrm{C}_{4} \mathrm{H}_{7}$ & $1.26 \mathrm{e} 8$ & 7942 & 0 \\
\hline$a C_{4} H_{7} \rightarrow C_{4} H_{6}+H$ & $1.0 \mathrm{e} 14$ & 204820 & 0 \\
\hline $\mathrm{C}_{4} \mathrm{H}_{6}+\mathrm{H} \rightarrow 4-\mathrm{C}_{4} \mathrm{H}_{7}$ & $3.98 \mathrm{e} 7$ & 8360 & 0 \\
\hline $4-C_{4} H_{7} \rightarrow C_{4} H_{6}+H$ & $1.0 \mathrm{e} 13$ & 142120 & 0 \\
\hline$a C_{4} H_{7} \rightarrow 4-C_{4} H_{7}$ & $2.51 \mathrm{e} 13$ & 204820 & 0 \\
\hline $4-C_{4} H_{7} \rightarrow a C_{4} H_{7}$ & $5.01 \mathrm{e} 12$ & 146300 & 0 \\
\hline $\mathrm{C}_{4} \mathrm{H}_{6}+\mathrm{C}_{2} \mathrm{H}_{3} \rightarrow \mathrm{CyC}_{5} \mathrm{H}_{6}+\mathrm{CH}_{3}$ & $1.0 \mathrm{e} 5$ & 20900 & 0 \\
\hline $\mathrm{C}_{4} \mathrm{H}_{6}+\mathrm{CH}_{3} \rightarrow i \mathrm{C}_{4} \mathrm{H}_{5}+\mathrm{CH}_{4}$ & $7.0 \mathrm{e} 7$ & 45980 & 0 \\
\hline \multicolumn{4}{|l|}{ Reactions of vinylacetylene $C_{4} H_{4}$} \\
\hline Reaction & $A$ & $E_{a}$ & $\beta$ \\
\hline $\mathrm{C}_{4} \mathrm{H}_{4}+\mathrm{CH}_{3} \rightarrow n \mathrm{C}_{4} \mathrm{H}_{3}+\mathrm{CH}_{4}$ & $7.0 \mathrm{e} 7$ & 77748 & 0 \\
\hline $\mathrm{C}_{2} \mathrm{H}_{4}+\mathrm{C}_{2} \mathrm{H} \rightarrow \mathrm{C}_{4} \mathrm{H}_{4}+\mathrm{H}$ & $3.1 \mathrm{e} 8$ & 60610 & 0 \\
\hline $\mathrm{C}_{4} \mathrm{H}_{4}+\mathrm{CH}_{3} \rightarrow i \mathrm{C}_{4} \mathrm{H}_{3}+\mathrm{CH}_{4}$ & $7.0 \mathrm{e} 7$ & 60610 & 0 \\
\hline$i C_{4} H_{5}+H \rightarrow C_{4} H_{4}+H_{2}$ & $3.0 \mathrm{e} 1$ & 4180 & 2.0 \\
\hline$i \mathrm{C}_{4} \mathrm{H}_{5}+\mathrm{H} \rightarrow \mathrm{C}_{4} \mathrm{H}_{6}$ & $3.53 \mathrm{e} 8$ & 17590 & -0.25 \\
\hline $\mathrm{C}_{2} \mathrm{H}_{3}+\mathrm{C}_{2} \mathrm{H}_{3} \rightarrow i \mathrm{C}_{4} \mathrm{H}_{5}+\mathrm{H}$ & $1.0 \mathrm{e} 8$ & 0 & 0 \\
\hline \multirow[t]{2}{*}{$i C_{4} H_{5}(+M) \rightarrow H+C_{4} H_{4}(+M)$} & $1.0 \mathrm{e} 14$ & $2.09 \mathrm{e} 5$ & 0 \\
\hline & $(2.0 \mathrm{e} 9)$ & $(1.756 \mathrm{e} 4)$ & $(0)$ \\
\hline
\end{tabular}


Reactions of diacetylene $C_{4} H_{2}$

\begin{tabular}{llll}
\hline Reaction & $A$ & $E_{a}$ & $\beta$ \\
\hline$C_{4} H_{2}+H \rightarrow C_{2} H_{2}+C_{2} H$ & $6.0 \mathrm{e} 8$ & 64372 & 0 \\
$i C_{4} H_{3}+H \rightarrow C_{4} H_{2}+H_{2}$ & $5.0 \mathrm{e} 7$ & 0 & 0 \\
$i C_{4} H_{3} \rightarrow n C_{4} H_{3}$ & $1.5 \mathrm{e} 13$ & 283404 & 0 \\
$n C_{4} H_{3} \rightarrow i C_{4} H_{3}$ & $5.96 \mathrm{e} 12$ & $2.06 \mathrm{e} 5$ & 0.62 \\
$n C_{4} H_{3}(+M) \rightarrow C_{4} H_{2}+H(+M)$ & $1.0 \mathrm{e} 14$ & $1.51 \mathrm{e} 5$ & 0 \\
& $(1.0 \mathrm{e} 8)$ & $(125400)$ & $(0)$ \\
\hline
\end{tabular}

Reactions of allene $a C_{3} H_{4}$

\begin{tabular}{llll}
\hline Reaction & $A$ & $E_{a}$ & $\beta$ \\
\hline$a C_{3} H_{4} \rightarrow p C_{3} H_{4}$ & $2.5 \mathrm{e} 12$ & 246620 & 0 \\
$a C_{3} H_{4}+a C_{3} H_{5} \rightarrow C_{3} H_{3}+C_{3} H_{6}$ & $2.0 \mathrm{e} 6$ & 32186 & 0 \\
$a C_{3} H_{4}+C H_{3} \rightarrow C_{3} H_{3}+C H_{4}$ & $2.0 \mathrm{e} 6$ & 32186 & 0 \\
$a C_{3} H_{5}+H \rightarrow a C_{3} H_{4}+H_{2}$ & $5.0 \mathrm{e} 7$ & 0 & 0 \\
$a C_{3} H_{5}+C H_{3} \rightarrow a C_{3} H_{4}+C H_{4}$ & $3.0 \mathrm{e} 6$ & -418 & -0.32 \\
$a C_{3} H_{5}+C_{2} H_{3} \rightarrow a C_{3} H_{4}+C_{2} H_{4}$ & $2.4 \mathrm{e} 6$ & 0 & 0 \\
$a C_{3} H_{5}+C_{2} H_{5} \rightarrow a C_{3} H_{4}+C_{2} H$ & $69.6 \mathrm{e} 5$ & 0 & 0 \\
\hline
\end{tabular}

Reactions of propyne $p C_{3} H_{4}$

\begin{tabular}{llll}
\hline Reaction & $A$ & $E_{a}$ & $\beta$ \\
\hline$p C_{3} H_{4} \rightarrow a C_{3} H_{4}$ & $2.1 \mathrm{e} 12$ & 250800 & 0 \\
$p C_{3} H_{4}+H \rightarrow C_{3} H_{3}+H_{2}$ & $1.7 \mathrm{e}-1$ & 10450 & 2.5 \\
$p C_{3} H_{4}+C H_{3} \rightarrow C_{3} H_{3}+C H_{4}$ & $2.2 \mathrm{e}-6$ & 23826 & 3.5 \\
$p C_{3} H_{4}+C_{2} H_{5} \rightarrow C_{3} H_{3}+C_{2} H_{6}$ & $2.2 \mathrm{e}-6$ & 27588 & 3.5 \\
$p C_{3} H_{4} \rightarrow C_{2} H+C H_{3}$ & $4.2 \mathrm{e} 16$ & 418000 & 0 \\
$C_{2} H+C H_{3} \rightarrow p C_{3} H_{4}$ & $3.0368 \mathrm{e} 9$ & -68915 & -0.85 \\
$p C_{3} H_{4}+H(+M) \rightarrow v C_{3} H_{5}(+M)$ & $6.5 \mathrm{e} 6$ & 8360 & 0 \\
& $(8.45 \mathrm{e} 27)$ & $(2.75 \mathrm{e} 4)$ & $(-7.27)$ \\
\hline
\end{tabular}


Formation of benzene $\mathrm{C}_{6} \mathrm{H}_{6}$ and of toluene $\mathrm{C}_{6} \mathrm{H}_{5} \mathrm{CH}_{3}$

\begin{tabular}{|c|c|c|c|}
\hline Reaction & $A$ & $E_{a}$ & $\beta$ \\
\hline$a C_{3} H_{4}+C_{3} H_{3} \rightarrow C_{6} H_{6}+H$ & $1.4 \mathrm{e} 6$ & 41800 & 0 \\
\hline $\mathrm{C}_{3} \mathrm{H}_{3}+\mathrm{C}_{3} \mathrm{H}_{3} \rightarrow \mathrm{C}_{6} \mathrm{H}_{6}$ & $1.0 \mathrm{e} 6$ & 0 & 0 \\
\hline $\mathrm{CyC}_{6} \mathrm{H}_{8}+\mathrm{CH}_{3} \rightarrow \mathrm{CyC}_{6} \mathrm{H}_{7}+\mathrm{CH}_{4}$ & $2.2 \mathrm{e}-6$ & 29887 & 2.5 \\
\hline $\mathrm{CyC}_{6} \mathrm{H}_{8} \rightarrow \mathrm{CyC}_{6} \mathrm{H}_{7}+\mathrm{H}$ & $5.0 \mathrm{e} 15$ & 302339 & 0 \\
\hline $\mathrm{CyC}_{6} \mathrm{H}_{7}+\mathrm{H} \rightarrow \mathrm{CyC}_{6} \mathrm{H}_{8}$ & $2.51 \mathrm{e} 9$ & 702.26 & -0.50 \\
\hline $\mathrm{CyC}_{6} \mathrm{H}_{7} \rightarrow \mathrm{C}_{6} \mathrm{H}_{6}+\mathrm{H}$ & $1.24 \mathrm{e} 10$ & $1.197 \mathrm{e} 5$ & -1.28 \\
\hline $\mathrm{C}_{6} \mathrm{H}_{6}+\mathrm{H} \rightarrow \mathrm{C}_{6} \mathrm{H}_{5}+\mathrm{H}_{2}$ & $2.5 \mathrm{e} 8$ & 68134 & 0 \\
\hline $\mathrm{C}_{6} \mathrm{H}_{6}+\mathrm{CH}_{3} \rightarrow \mathrm{C}_{6} \mathrm{H}_{5}+\mathrm{CH}_{4}$ & $2.0 \mathrm{e} 6$ & 62700 & 0 \\
\hline $\mathrm{C}_{6} \mathrm{H}_{6}+\mathrm{CH}_{3} \rightarrow \mathrm{C}_{6} \mathrm{H}_{5} \mathrm{CH}_{3}+\mathrm{H}$ & $8.39 \mathrm{e} 1$ & 58712 & 1.34 \\
\hline $\mathrm{C}_{6} \mathrm{H}_{5}+\mathrm{CH}_{3} \rightarrow \mathrm{C}_{6} \mathrm{H}_{5} \mathrm{CH}_{3}$ & $1.07 \mathrm{e} 8$ & 3680 & -0.24 \\
\hline $\mathrm{C}_{6} \mathrm{H}_{5} \mathrm{CH}_{3}+\mathrm{CH}_{3} \rightarrow \mathrm{C}_{6} \mathrm{H}_{5} \mathrm{CH}_{2}+\mathrm{CH}_{4}$ & $3.16 \mathrm{e} 5$ & 39710 & 0 \\
\hline $\mathrm{C}_{6} \mathrm{H}_{5} \mathrm{CH}_{3}+\mathrm{H} \rightarrow \mathrm{C}_{6} \mathrm{H}_{5} \mathrm{CH}_{2}+\mathrm{H}_{2}$ & $3.98 \mathrm{e}-4$ & 13042 & 3.44 \\
\hline $\mathrm{C}_{6} \mathrm{H}_{5} \mathrm{CH}_{2}+\mathrm{H}_{2} \rightarrow \mathrm{C}_{6} \mathrm{H}_{5} \mathrm{CH}_{3}+\mathrm{H}$ & $7.04 \mathrm{e} 0$ & 57037 & 3.58 \\
\hline $\mathrm{C}_{6} \mathrm{H}_{5} \mathrm{CH}_{3}+\mathrm{H} \rightarrow \mathrm{C}_{6} \mathrm{H}_{6}+\mathrm{CH}_{3}$ & $1.2 \mathrm{e} 7$ & 21519 & 0 \\
\hline \multicolumn{4}{|l|}{ Formation of naphthalene $C_{10} H_{8}$} \\
\hline Reaction & $A$ & $E_{a}$ & $\beta$ \\
\hline $\mathrm{C}_{2} \mathrm{H}_{2}+\mathrm{C}_{6} \mathrm{H}_{5} \rightarrow \mathrm{C}_{6} \mathrm{H}_{5} \mathrm{C}_{2} \mathrm{H}+\mathrm{H}$ & $5.1 \mathrm{e} 32$ & 123728 & -7.1 \\
\hline $\mathrm{C}_{6} \mathrm{H}_{5} \mathrm{C}_{2} \mathrm{H}+\mathrm{H} \rightarrow \mathrm{C}_{6} \mathrm{H}_{4} \mathrm{C}_{2} \mathrm{H}+\mathrm{H}_{2}$ & $2.5 \mathrm{e} 8$ & 66880 & 0 \\
\hline $\mathrm{C}_{6} \mathrm{H}_{5} \mathrm{C}_{2} \mathrm{H}+\mathrm{CH}_{3} \rightarrow \mathrm{C}_{6} \mathrm{H}_{4} \mathrm{C}_{2} \mathrm{H}+\mathrm{CH}_{4}$ & $2.0 \mathrm{e} 6$ & 62700 & 0 \\
\hline $\mathrm{C}_{6} \mathrm{H}_{4} \mathrm{C}_{2} \mathrm{H}+\mathrm{C}_{2} \mathrm{H}_{2} \rightarrow \mathrm{C}_{10} \mathrm{H}_{7}$ & $1.4 \mathrm{e} 46$ & 108680 & -11.58 \\
\hline $\mathrm{C}_{10} \mathrm{H}_{7}+\mathrm{H} \rightarrow \mathrm{C}_{10} \mathrm{H}_{8}$ & $5.45 \mathrm{e} 36$ & 61446 & -8.74 \\
\hline $\mathrm{C}_{10} \mathrm{H}_{8}+\mathrm{H} \rightarrow \mathrm{C}_{10} \mathrm{H}_{7}+\mathrm{H}_{2}$ & $2.5 \mathrm{e} 8$ & 66880 & 0 \\
\hline $\mathrm{C}_{10} \mathrm{H}_{8}+\mathrm{CH}_{3} \rightarrow \mathrm{C}_{10} \mathrm{H}_{7}+\mathrm{CH}_{4}$ & $2.0 \mathrm{e} 6$ & 62700 & 0 \\
\hline $\mathrm{CyC}_{5} \mathrm{H}_{6} \rightarrow \mathrm{H}+\mathrm{CyC}_{5} \mathrm{H}_{5}$ & $2.51 \mathrm{e} 15$ & 307230 & 0 \\
\hline $\mathrm{H}+\mathrm{CyC}_{5} \mathrm{H}_{6} \rightarrow \mathrm{H}_{2}+\mathrm{Cy} \mathrm{C}_{5} \mathrm{H}_{5}$ & $2.51 \mathrm{e} 8$ & 33400 & 0 \\
\hline$C y C_{5} H_{5}+C y C_{5} H_{5} \rightarrow C_{10} H_{8}+H+H$ & $2.0 \mathrm{e} 7$ & 33440 & 0 \\
\hline
\end{tabular}


Additional routes to cyclic compounds (mechanism C)

\begin{tabular}{|c|c|c|c|}
\hline Reaction & $A$ & $E_{a}$ & $\beta$ \\
\hline $\mathrm{C}_{2} \mathrm{H}_{3}+\mathrm{C}_{4} \mathrm{H}_{4} \rightarrow \mathrm{C}_{6} \mathrm{H}_{6}+\mathrm{H}$ & $3.0 \mathrm{e} 5$ & 12540 & 0 \\
\hline $\mathrm{C}_{3} \mathrm{H}_{3}+\mathrm{C}_{2} \mathrm{H}_{3} \rightarrow \mathrm{CyC}_{5} \mathrm{H}_{5}+\mathrm{H}$ & $9.63 \mathrm{e} 34$ & $1.2047 \mathrm{e} 5$ & -7.28 \\
\hline $\mathrm{CyC}_{5} \mathrm{H}_{5}+\mathrm{H} \rightarrow \mathrm{C}_{3} \mathrm{H}_{3}+\mathrm{C}_{2} \mathrm{H}_{3}$ & $2.1088 \mathrm{e}+56$ & $3.1712 \mathrm{e}+05$ & -12.683 \\
\hline \multicolumn{4}{|c|}{ Reactions involving 1,2-butadiene $1,2-C_{4} H_{6}$ (mechanism C) } \\
\hline Reaction & $A$ & $E_{a}$ & $\beta$ \\
\hline $\mathrm{C}_{3} \mathrm{H}_{3}+\mathrm{CH}_{3} \rightarrow 1,2-\mathrm{C}_{4} H_{6}$ & $3.2558 \mathrm{e} 11$ & 2183.7 & -1.4786 \\
\hline $\mathrm{CH}_{3}+a \mathrm{C}_{3} \mathrm{H}_{4} \rightarrow 1,2-\mathrm{C}_{4} \mathrm{H}_{6}+\mathrm{H}$ & 36.969 & 47872 & 1.3583 \\
\hline$i C_{4} H_{5}+H \rightarrow 1,2-C_{4} H_{6}$ & $1.17 \mathrm{e} 8$ & $3.82 \mathrm{e} 4$ & 0.04 \\
\hline$i C_{4} H_{5}+H_{2} \rightarrow 1,2-C_{4} H_{6}+H$ & $1.43 \mathrm{e}-3$ & $9.34 \mathrm{e} 4$ & 3.05 \\
\hline $\mathrm{C}_{4} \mathrm{H}_{6} \rightarrow 1,2-\mathrm{C}_{4} \mathrm{H}_{6}$ & $2.955 \mathrm{e} 16$ & $3.29 \mathrm{e} 5$ & -0.704 \\
\hline$i \mathrm{C}_{4} \mathrm{H}_{5}+\mathrm{CH}_{4} \rightarrow 1,2-\mathrm{C}_{4} \mathrm{H}_{6}+\mathrm{CH}_{3}$ & $1.18 \mathrm{e}-6$ & $1.12 \mathrm{e} 5$ & 3.79 \\
\hline $1,2-C_{4} H_{6} \rightarrow C_{4} H_{6}$ & $3.0 \mathrm{e} 13$ & $2.72 \mathrm{e} 5$ & 0 \\
\hline $1,2-\mathrm{C}_{4} \mathrm{H}_{6} \rightarrow \mathrm{C}_{3} \mathrm{H}_{3}+\mathrm{CH}_{3}$ & $1.0 \mathrm{e} 12$ & $2.469 \mathrm{e} 5$ & 0 \\
\hline $1,2-C_{4} H_{6} \rightarrow i C_{4} H_{5}+H$ & $4.2 \mathrm{e} 15$ & $3.874 \mathrm{e} 5$ & 0 \\
\hline $1,2-C_{4} H_{6}+H \rightarrow C_{2} H_{4}+C_{2} H_{3}$ & $4.0 \mathrm{e} 5$ & 0 & 0 \\
\hline $1,2-C_{4} H_{6}+H \rightarrow C_{3}+a C_{3} H_{4}$ & $2.0 \mathrm{e} 7$ & $8.968 \mathrm{e} 3$ & 0 \\
\hline $1,2-C_{4} H_{6}+H \rightarrow i C_{4} H_{5}+H_{2}$ & $5.0 \mathrm{e} 1$ & $2.092 \mathrm{e} 4$ & 2.0 \\
\hline $1,2-C_{4} H_{6}+\mathrm{CH}_{3} \rightarrow i C_{4} H_{5}+\mathrm{CH}_{4}$ & $2.2 \mathrm{e}-6$ & $2.385 \mathrm{e} 4$ & 3.5 \\
\hline $1,2-C_{4} H_{6}+C_{2} H_{5} \rightarrow i C_{4} H_{5}+C_{2} H_{6}$ & $2.2 \mathrm{e}-6$ & $2.761 \mathrm{e} 4$ & 3.5 \\
\hline
\end{tabular}


Reactions of methylallenyl and methylpropynyl (mechanism C)

\begin{tabular}{|c|c|c|c|}
\hline Reaction & $A$ & $E_{a}$ & $\beta$ \\
\hline $1,2-C_{4} H_{6}+H \rightarrow p 2 r 1-C_{4} H_{5}+H_{2}$ & $1.50 \mathrm{e} 1$ & $2.51 \mathrm{e} 4$ & 2.0 \\
\hline$i C_{4} H_{5}+H \rightarrow p 2 r 1-C_{4} H_{5}+H$ & $3.00 \mathrm{e} 7$ & 0 & 0 \\
\hline$p 2 r 1-C_{4} H_{5}+H \rightarrow C_{3}+C_{3} H_{3}$ & $1.00 \mathrm{e} 8$ & 0 & 0 \\
\hline$p 2 r 1-C_{4} H_{5}+H \rightarrow C_{4} H_{4}+H_{2}$ & $1.00 \mathrm{e} 8$ & $3.34 \mathrm{e} 4$ & 0 \\
\hline$p 2 r 1-C_{4} H_{5}+H_{2} \rightarrow 1,2-C_{4} H_{6}+H$ & 0.0030841 & 96141 & 2.9185 \\
\hline \multirow[t]{2}{*}{$p 2 r 1-C_{4} H_{5}(+M) \rightarrow C_{4} H_{4}+H(+M)$} & $1.00 \mathrm{e} 13$ & $2.34 \mathrm{e} 5$ & 0 \\
\hline & $(2.00 \mathrm{e} 8)$ & $(2.01 \mathrm{e} 5)$ & $(0)$ \\
\hline \multirow{3}{*}{$C_{4} H_{4}+H(+M) \rightarrow p 2 r 1-C_{4} H_{5}(+M)$} & $1.328 \mathrm{e}+06$ & 14303 & -0.051529 \\
\hline & $(26.557)$ & $(-19137)$ & $(-$ \\
\hline & & & $0.051517)$ \\
\hline$p 2 r 1-C_{4} H_{5}+C_{3} H_{3} \rightarrow C_{6} H_{5} C_{2}+H$ & $3.00 \mathrm{e} 6$ & 0 & 0 \\
\hline $\mathrm{C}_{6} \mathrm{H}_{5} \mathrm{CH}_{2}+\mathrm{H} \rightarrow p 2 r 1-\mathrm{C}_{4} \mathrm{H}_{5}+\mathrm{C}_{3} \mathrm{H}_{3}$ & $2.399 \mathrm{e}+22$ & $2.1202 \mathrm{e}+05$ & -1.4999 \\
\hline $\begin{array}{l}p 2 r 1-C_{4} H_{5}+p 2 r 1-C_{4} H_{5} \rightarrow \mathrm{CH}_{3} C_{6} H_{4} C_{2} H_{2} \\
+H\end{array}$ & $3.00 \mathrm{e} 6$ & 0 & 0 \\
\hline $1,2-C_{4} H_{6}+H \rightarrow p 1 r 3-C_{4} H_{5}+H_{2}$ & $3.0 \mathrm{e} 1$ & $2.72 \mathrm{e} 4$ & 2.0 \\
\hline$p 1 r 3-C_{4} H_{5}+H \rightarrow C_{3}+C_{3} H_{3}$ & $1.00 \mathrm{e} 8$ & 0 & 0 \\
\hline \multirow[t]{2}{*}{$p 1 r 3-C_{4} H_{5}(+M) \rightarrow C_{4} H_{4}+H(+M)$} & $1.00 \mathrm{e} 13$ & $2.05 \mathrm{e} 5$ & 0 \\
\hline & $(2.00 \mathrm{e} 8)$ & $(1.71 \mathrm{e} 5)$ & $(0)$ \\
\hline$p 1 r 3-C_{4} H_{5}+C_{3} H_{3} \rightarrow C_{6} H_{5} C_{2}+H$ & $3.00 \mathrm{e} 6$ & 0 & 0 \\
\hline $\begin{array}{l}p 1 r 3-C_{4} H_{5}+p 1 r 3-C_{4} H_{5} \rightarrow \mathrm{CH}_{3} C_{6} H_{4} C_{2} H_{2} \\
+H\end{array}$ & $3.00 \mathrm{e} 6$ & 0 & 0 \\
\hline
\end{tabular}


HACA from naphthalene to phenanthrene $C_{14} H_{10}$ (mechanism C)

\begin{tabular}{llll}
\hline Reaction & $A$ & $E_{a}$ & $\beta$ \\
\hline$C_{10} H_{7}+C_{2} H_{2} \rightarrow C_{10} H_{7} C_{2} H+H$ & $5.1 \mathrm{e} 38$ & $1.24 \mathrm{e} 5$ & -7.1 \\
$C_{10} H_{7} C_{2} H+H \rightarrow C_{10} H_{6} C_{2} H+H_{2}$ & $2.5 \mathrm{e} 14$ & $6.69 \mathrm{e} 5$ & 0 \\
$C_{10} H_{7} C_{2} H+H \rightarrow C_{10} H_{7}+C_{2} H_{2}$ & $6.89 \mathrm{e} 45$ & 91876 & -8.87 \\
$C_{10} H_{7} C_{2} H+C H_{3} \rightarrow C_{10} H_{6} C_{2} H+C H_{4}$ & $2.0 \mathrm{e} 12$ & $6.28 \mathrm{e} 4$ & 0 \\
$C_{10} H_{7} C_{2} H \rightarrow C_{10} H_{6} C_{2} H+H$ & $4.38 \mathrm{e} 94$ & $5.21 \mathrm{e} 5$ & -24.25 \\
$C_{10} H_{6} C_{2} H+H \rightarrow C_{10} H_{7} C_{2} H$ & $5.45 \mathrm{e} 42$ & $6.15 \mathrm{e} 4$ & -8.74 \\
$C_{10} H_{6} C_{2} H+H_{2} \rightarrow C_{10} H_{7} C_{2} H+H$ & $1.27 \mathrm{e} 24$ & $8.12 \mathrm{e} 5$ & 0 \\
$C_{10} H_{6} C_{2} H+C H_{4} \rightarrow C_{10} H_{7} C_{2} H+C H_{3}$ & $2.24 \mathrm{e}-31$ & 44161 & 15.28 \\
$C_{10} H_{6} C_{2} H+C_{2} H_{2} \rightarrow$ phenanthryl & $1.4 \mathrm{e} 52$ & $1.09 \mathrm{e} 5$ & -11.58 \\
phenanthryl $+H \rightarrow$ phenanthrene & $5.45 \mathrm{e} 42$ & $6.15 \mathrm{e} 4$ & -8.74 \\
phenanthryl $\rightarrow C_{10} H_{6} C_{2} H+C_{2} H_{2}$ & $2.25 \mathrm{e} 127$ & $6.09 \mathrm{e} 5$ & -32.62 \\
phenanthryl $+H_{2} \rightarrow$ phenanthrene $+H$ & $4.91 \mathrm{e} 13$ & $6.94 \mathrm{e} 5$ & 0 \\
phenanthryl $+\mathrm{CH}_{4} \rightarrow$ phenanthrene $+C H_{3}$ & $1.86 \mathrm{e} 8$ & 74373 & 1.36 \\
phenanthrene $\rightarrow$ phenanthryl $+H$ & $4.72 \mathrm{e} 56$ & $4.94 \mathrm{e} 5$ & -10.60 \\
phenanthrene $+H \rightarrow$ phenanthryl $+H_{2}$ & $2.5 \mathrm{e} 14$ & $6.69 \mathrm{e} 5$ & 0 \\
phenanthrene $+\mathrm{CH}_{3} \rightarrow$ phenanthryl $+\mathrm{CH}_{4}$ & $2.0 \mathrm{e} 12$ & $6.28 \mathrm{e} 4$ & 0 \\
$C_{10} H_{7}+C_{2} H_{2} \rightarrow$ acenaph & $1.0 \mathrm{e} 14$ & $5.02 \mathrm{e} 4$ & -2.08 \\
acenaph $\rightarrow C_{10} H_{7}+C_{2} H_{2}$ & $1.75 \mathrm{e} 22$ & $3.57 \mathrm{e} 5$ & -1.30 \\
\hline & & & \\
\hline
\end{tabular}

Reactions of $\mathrm{o}$-xylene $\mathrm{CH}_{3} \mathrm{C}_{6} \mathrm{H}_{4} \mathrm{CH}_{3}$ (mechanism C)

\begin{tabular}{llll}
\hline Reaction & $A$ & $E_{a}$ & $\beta$ \\
\hline $\mathrm{CH}_{3} \mathrm{C}_{6} \mathrm{H}_{4} \mathrm{CH}_{2}+\mathrm{H} \rightarrow \mathrm{CH}_{3} \mathrm{C}_{6} \mathrm{H}_{4} \mathrm{CH}_{3}$ & $7.46 \mathrm{e} 7$ & $3.26 \mathrm{e} 2$ & 0 \\
$\mathrm{CH}_{3} \mathrm{C}_{6} \mathrm{H}_{4} \mathrm{CH}_{2}+\mathrm{H}_{2} \rightarrow \mathrm{CH}_{3} \mathrm{C}_{6} \mathrm{H}_{4} \mathrm{CH}_{3}+\mathrm{H}$ & $1.23 \mathrm{e}-6$ & 62171 & 3.87 \\
$\mathrm{CH}_{3} \mathrm{C}_{6} \mathrm{H}_{4} \mathrm{CH}_{2}+\mathrm{C}_{2} \mathrm{H}_{2} \rightarrow \mathrm{C}_{10} \mathrm{H}_{10}+\mathrm{H}$ & $3.2 \mathrm{e} 5$ & $2.93 \mathrm{e} 4$ & 0 \\
$\mathrm{CH}_{3} \mathrm{C}_{6} \mathrm{H}_{4} \mathrm{CH}_{3} \rightarrow \mathrm{CH}_{3} \mathrm{C}_{6} \mathrm{H}_{4} \mathrm{CH}_{2}+\mathrm{H}$ & $4.66 \mathrm{e} 15$ & $3.84 \mathrm{e} 5$ & -0.046 \\
$\mathrm{CH}_{3} \mathrm{C}_{6} \mathrm{H}_{4} \mathrm{CH}_{3}+\mathrm{H} \rightarrow \mathrm{CH}_{3} \mathrm{C}_{6} \mathrm{H}_{4} \mathrm{CH}_{2}+\mathrm{H}_{2}$ & $3.98 \mathrm{e}-4$ & $1.3 \mathrm{e} 4$ & 3.44 \\
\hline
\end{tabular}


Reactions of indene $C_{6} H_{4} C_{3} H_{4}$ (mechanism C)

\begin{tabular}{llll}
\hline Reaction & $A$ & $E_{a}$ & $\beta$ \\
\hline $\mathrm{C}_{6} \mathrm{H}_{5} \mathrm{CH}_{2}+\mathrm{C}_{2} \mathrm{H}_{2} \rightarrow$ indene $+H$ & $3.2 \mathrm{e} 5$ & $2.93 \mathrm{e} 4$ & 0 \\
indenyl $+\mathrm{H}_{2} \rightarrow$ indene $+H$ & $3.53 \mathrm{e}-4$ & $1.253 \mathrm{e} 5$ & 3.158 \\
indenyl $+\mathrm{H} \rightarrow$ indene & $2.0 \mathrm{e} 8$ & 0 & 0 \\
indenyl $+\mathrm{Cy} \mathrm{C}_{5} \mathrm{H}_{5} \rightarrow$ phenanthrene $+H+1.0 \mathrm{e} 7$ & $1.67 \mathrm{e} 4$ & 0 \\
$H$ & & & \\
indene $\rightarrow$ indenyl $+H$ & $8.14 \mathrm{e} 13$ & $3.021 \mathrm{e} 5$ & 0.515 \\
indene $+H \rightarrow \mathrm{C}_{6} \mathrm{H}_{5} \mathrm{CH}+\mathrm{H}_{2}+\mathrm{C}_{2}$ & $2.24 \mathrm{e} 7$ & $1.013 \mathrm{e} 5$ & -0.8828 \\
indene $+\mathrm{H} \rightarrow$ indenyl $+H_{2}$ & $2.19 \mathrm{e} 2$ & $1.25 \mathrm{e} 4$ & 1.77 \\
\hline
\end{tabular}

Reactions of biphenyl $C_{12} H_{10}$ (mechanism C)

\begin{tabular}{llll}
\hline Reaction & $A$ & $E_{a}$ & $\beta$ \\
\hline$C_{6} H_{5}+C_{6} H_{5} \rightarrow C_{12} H_{10}$ & $5.0 \mathrm{e} 6$ & 0 & 0 \\
$C_{6} H_{5}+C_{6} H_{6} \rightarrow C_{12} H_{10}+H$ & $4.0 \mathrm{e} 5$ & $1.67 \mathrm{e} 4$ & 0 \\
$C_{12} H_{10} \rightarrow C_{6} H_{5}+C_{6} H_{5}$ & $5.03 \mathrm{e} 33$ & $5.08 \mathrm{e} 5$ & -4.951 \\
$C_{12} H_{10}+H \rightarrow C_{6} H_{6}+C_{6} H_{5}$ & $1.65 \mathrm{e} 14$ & 30000 & -2.136 \\
\hline
\end{tabular}

Formation of fluoranthene $C_{16} H_{10}$ (mechanism C)

\begin{tabular}{llll}
\hline Reaction & $A$ & $E_{a}$ & $\beta$ \\
\hline$C_{10} H_{7}+C_{6} H_{5} \rightarrow C_{16} H_{10}+H+H$ & $5.0 \mathrm{e} 6$ & 0 & 0 \\
$C_{10} H_{7}+C_{6} H_{6} \rightarrow C_{16} H_{10}+H_{2}+H$ & $4.0 \mathrm{e} 5$ & $1.67 \mathrm{e} 4$ & 0 \\
\hline
\end{tabular}




\section{Figure Captions}

- Figure 1. Geometry of the resolution domain and boundary conditions.

- Figure 2. Computed species partial pressures vs. residence time at two temperatures. Comparison with FTIR data. Total pressure : $2000 \mathrm{~Pa}$. a) $\mathrm{C}_{3} \mathrm{H}_{8}$, b) $\mathrm{CH}_{4}$, c) $\mathrm{C}_{2} \mathrm{H}_{2}$, d) aC $\mathrm{C}_{3} H_{4}$, e) $\mathrm{C}_{4} H_{4}$, f) $\mathrm{C}_{4} H_{6}$, g) $\mathrm{C}_{6} H_{6}$, h) $\mathrm{C}_{10} H_{8}$.

- Figure 3. Reaction fluxes at $1273 \mathrm{~K}$, at a) $z=0.4$ and b) $z=0.5$; Propane decomposition.

- Figure 4. Reaction fluxes at $1273 \mathrm{~K}$, at a) $z=0.4$ and b) $z=0.5$; C3 compounds.

- Figure 5. Reaction fluxes at $1273 \mathrm{~K}$, at a) $z=0.4$ and b) $z=0.5$; C4 compounds.

- Figure 6. Reaction fluxes at $1273 \mathrm{~K}$, at a) $z=0.4$ and b) $z=0.5$; Formation of aromatic compounds.

- Figure 7. Main reaction pathways at a)low and b)high maturation conditions.

- Figure 8. Mass deposition rate vs. residence time at $T=1273 \mathrm{~K}$ and $P=2 k P a$ according to Lavenac [40]. See text for a description of zones (1) to $(4)$.

- Figure 9. Scaled concentration profiles of some species vs. residence time at $T=1273 K$ and $P=2 k P a$

- Figure 10. Comparison of experimental deposition rates with a fitted LangmuirHinshelwood mechanism 4.6 based on benzene and phenanthrene concentrations. 


\section{Table Captions}

- Table 1. Strategy for the study of propane pyrolysis. 


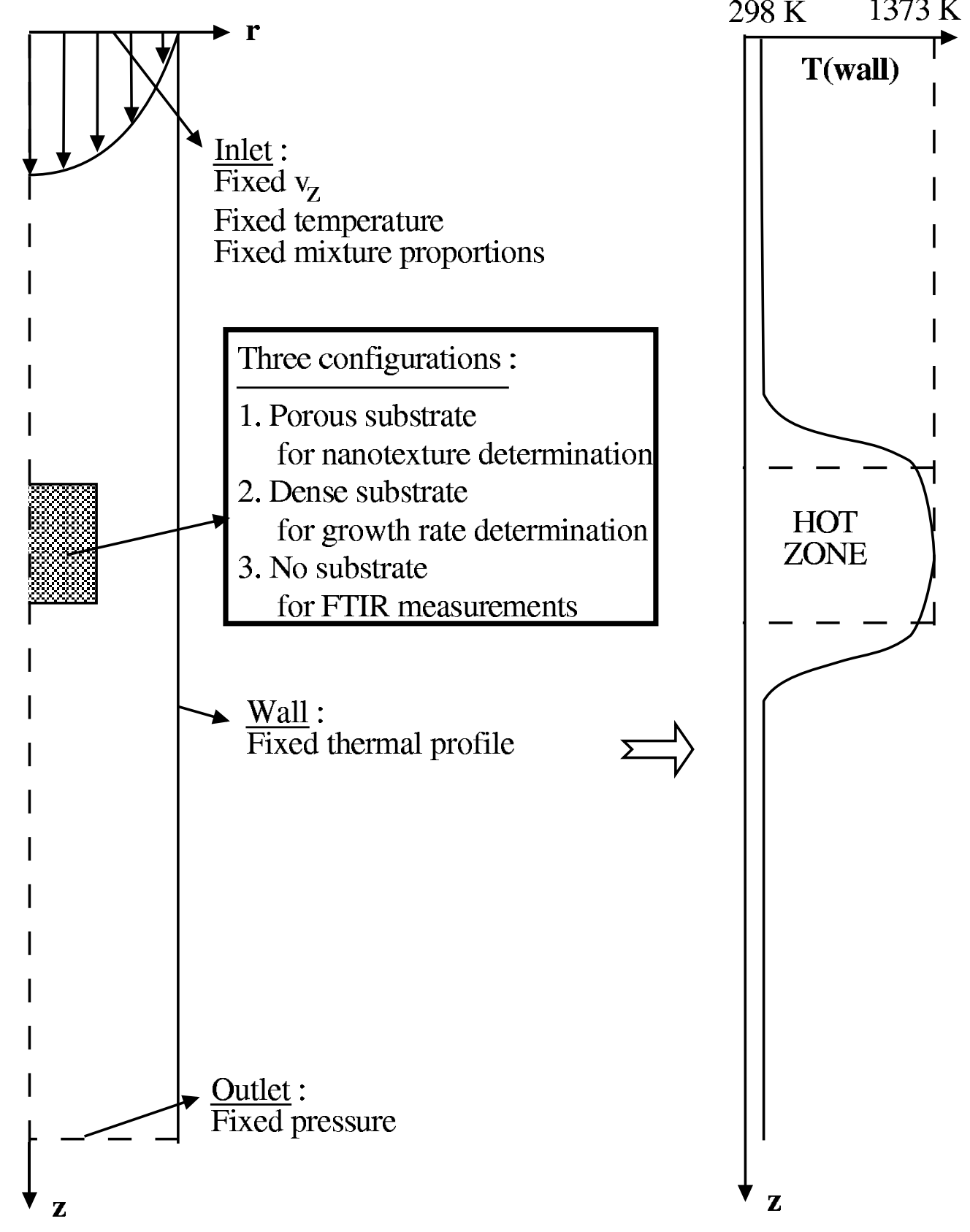

Figure 1: 


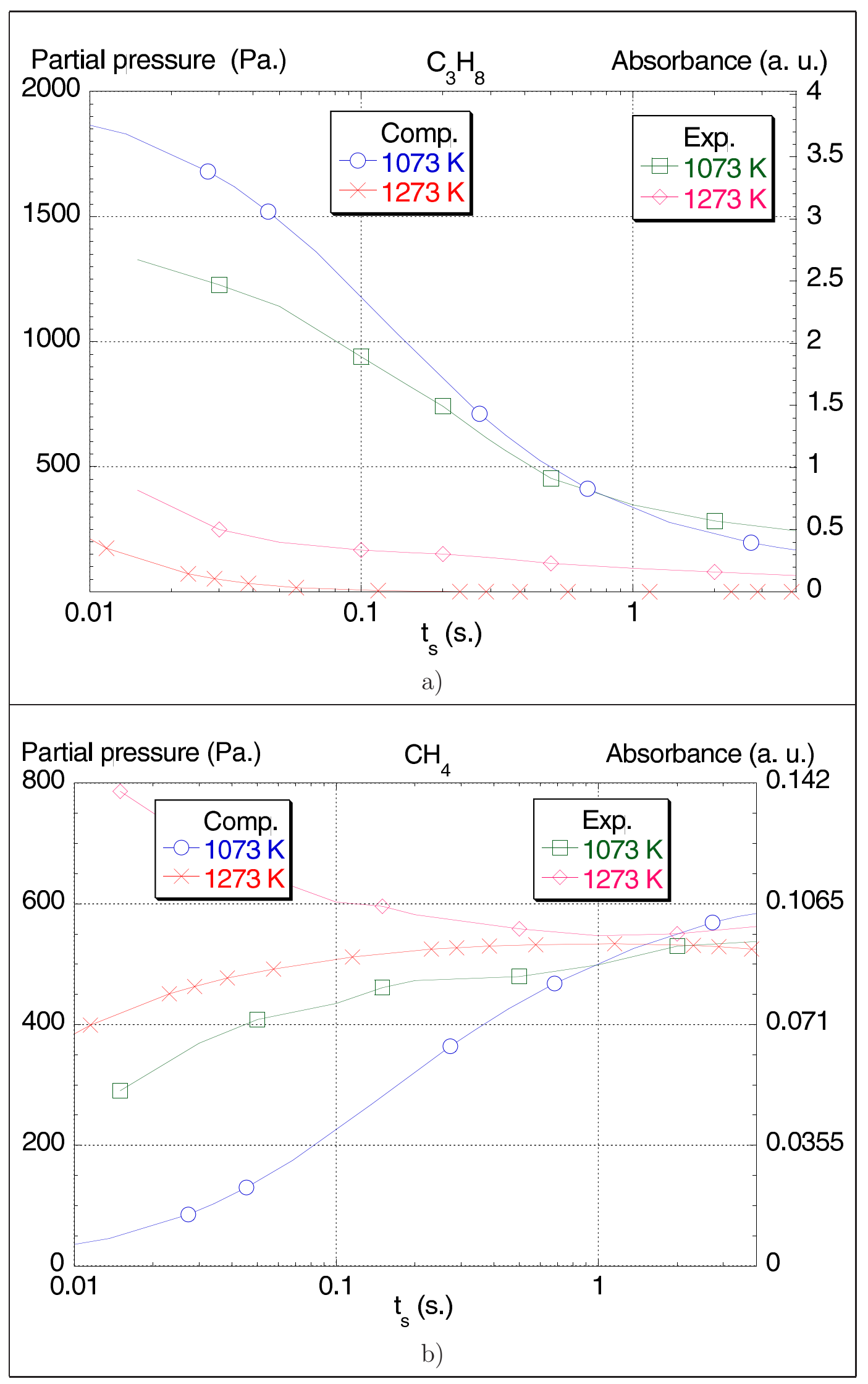

Figure 2: 


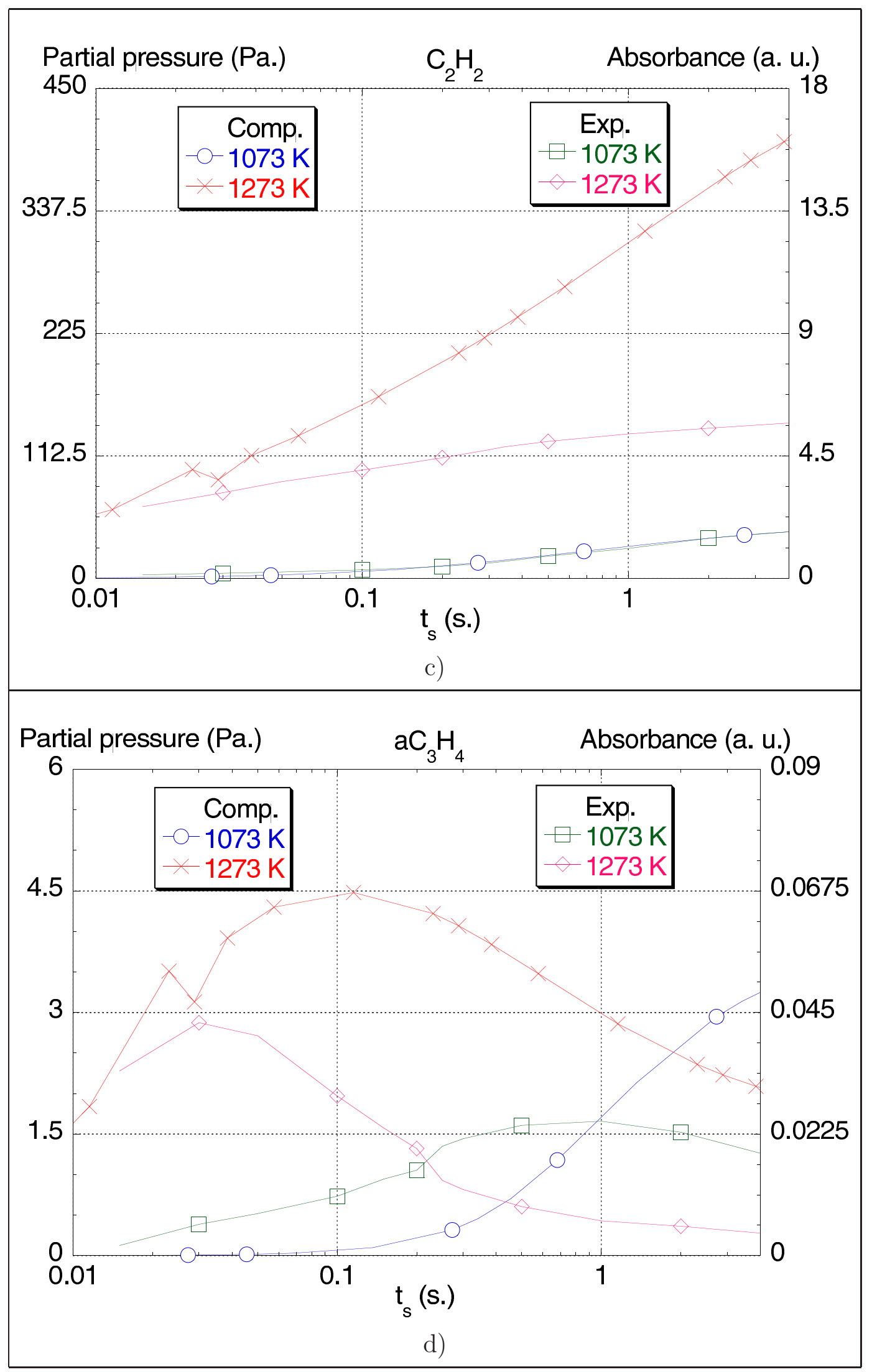

Figure 2 (cont.) : 


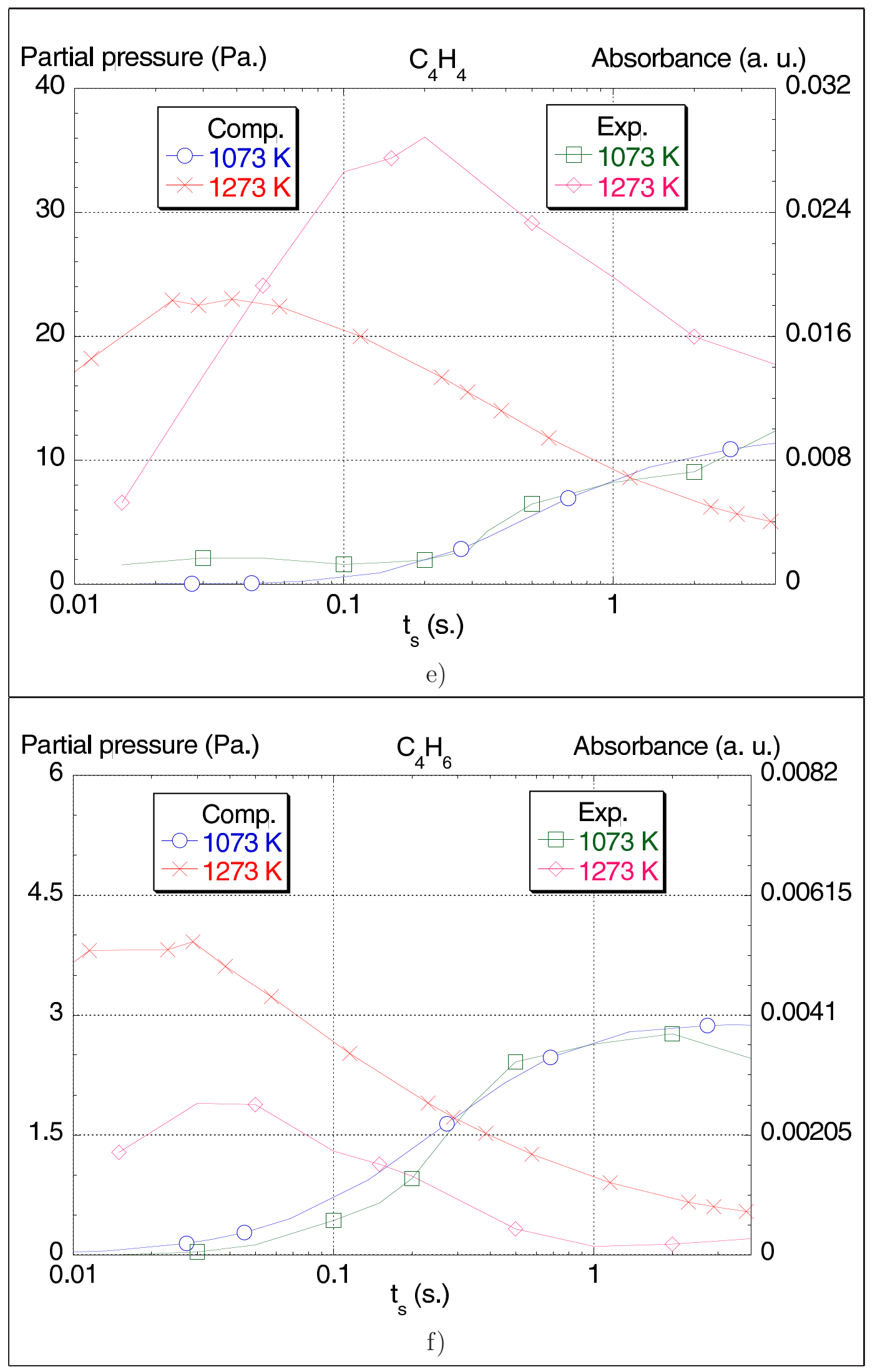

Figure 2 (cont.) : 


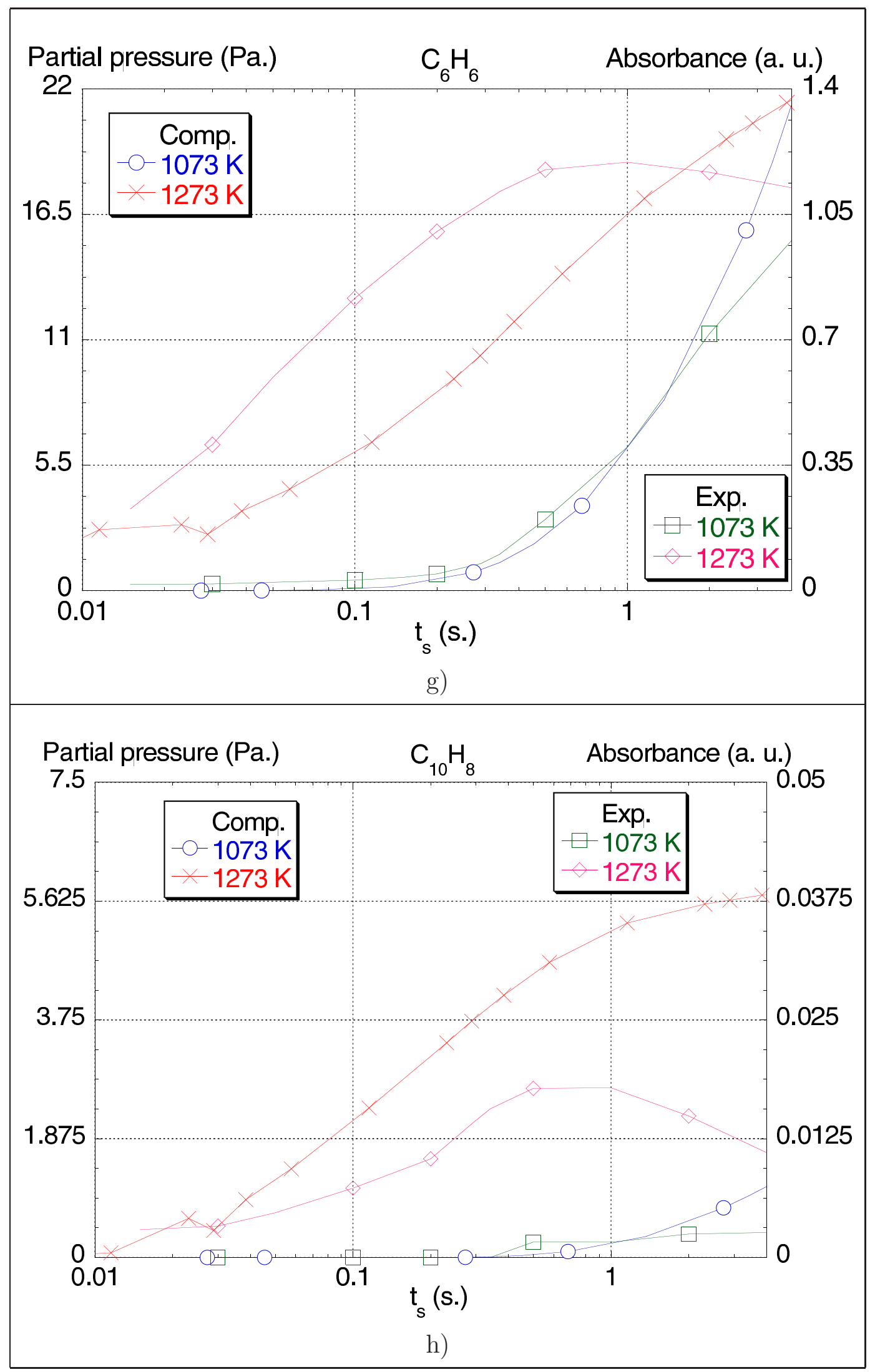

Figure 2 (cont.) : 


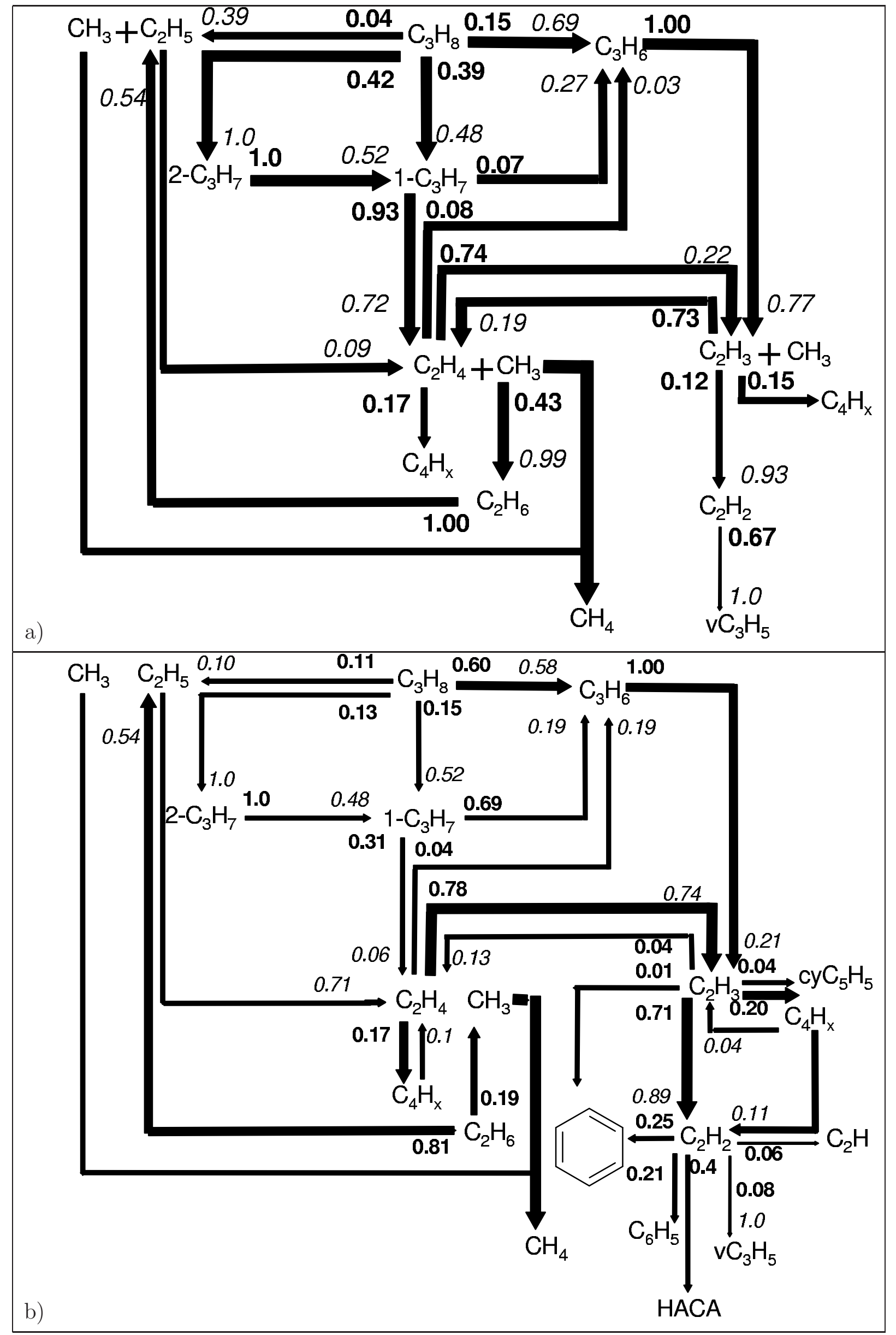

Figure 3: 


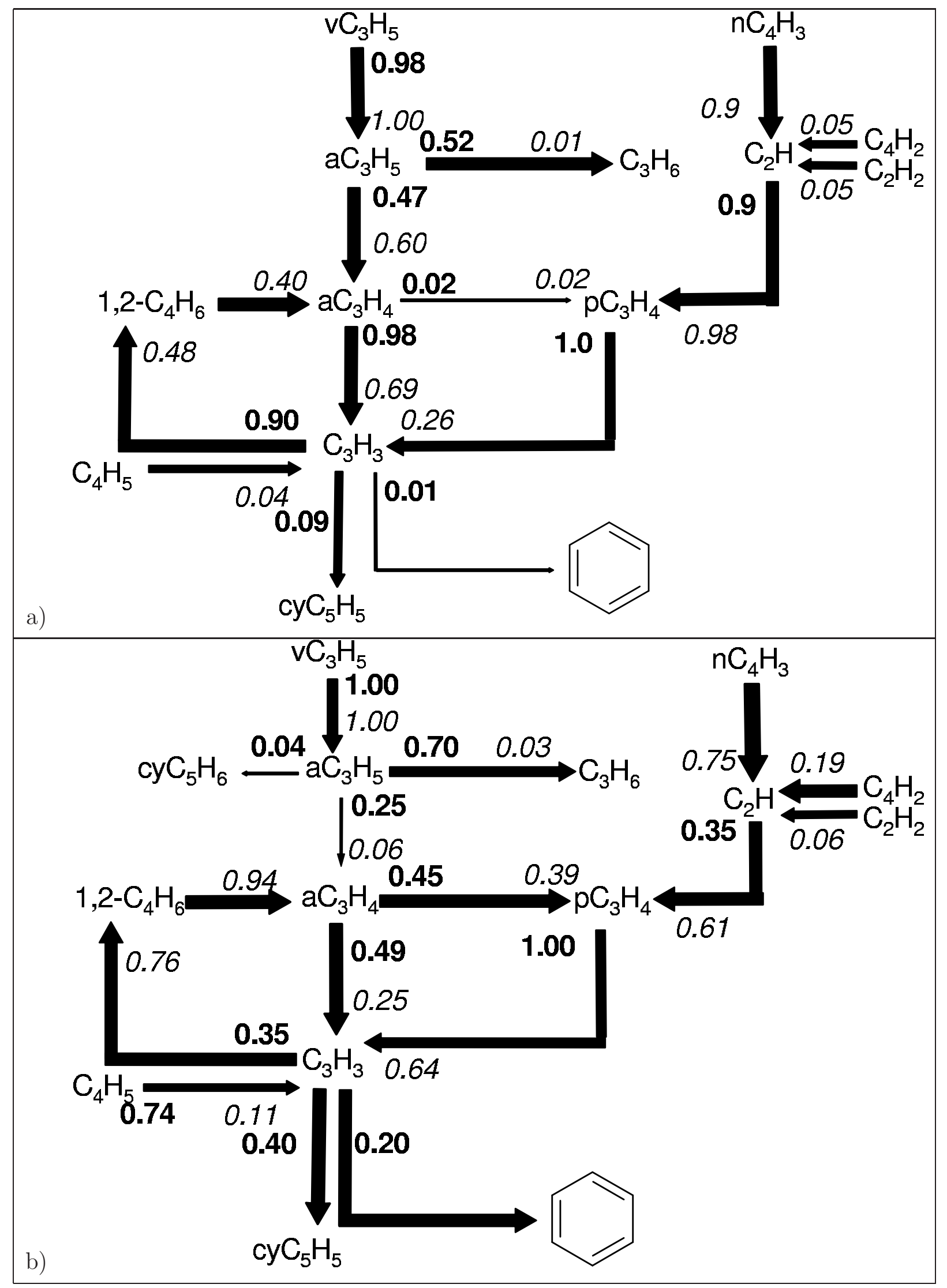

Figure 4: 


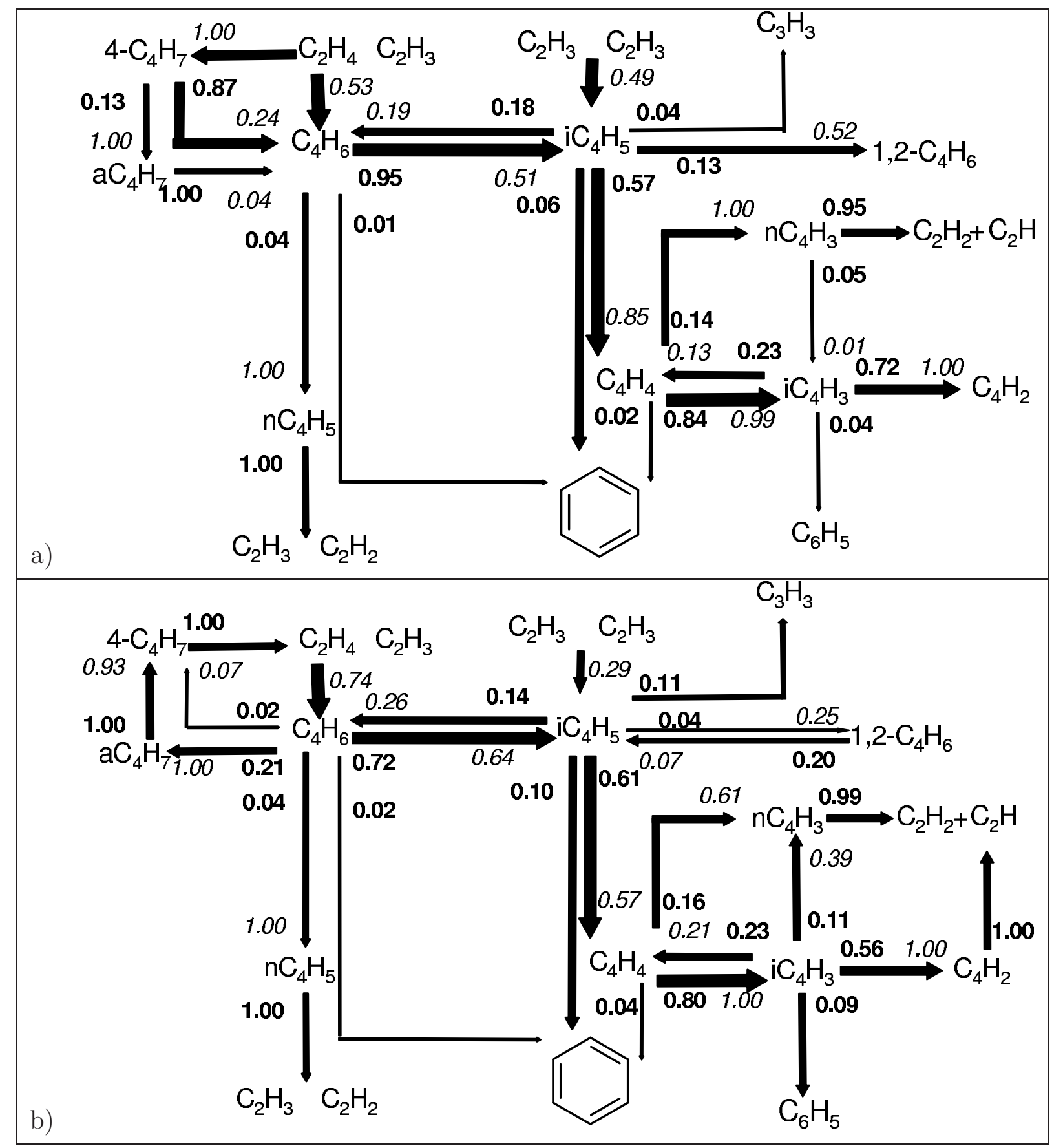

Figure 5: 


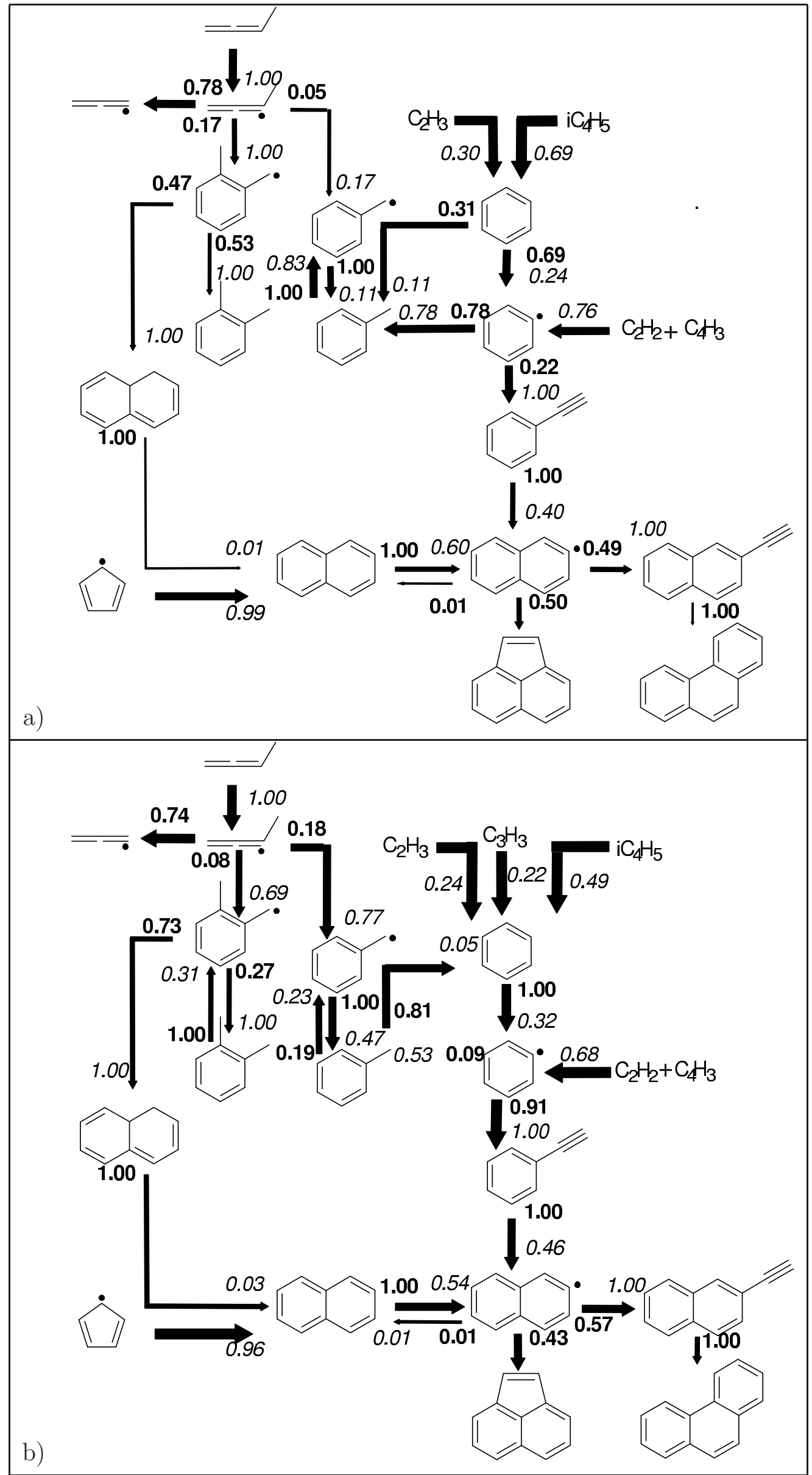

Figure 6: 


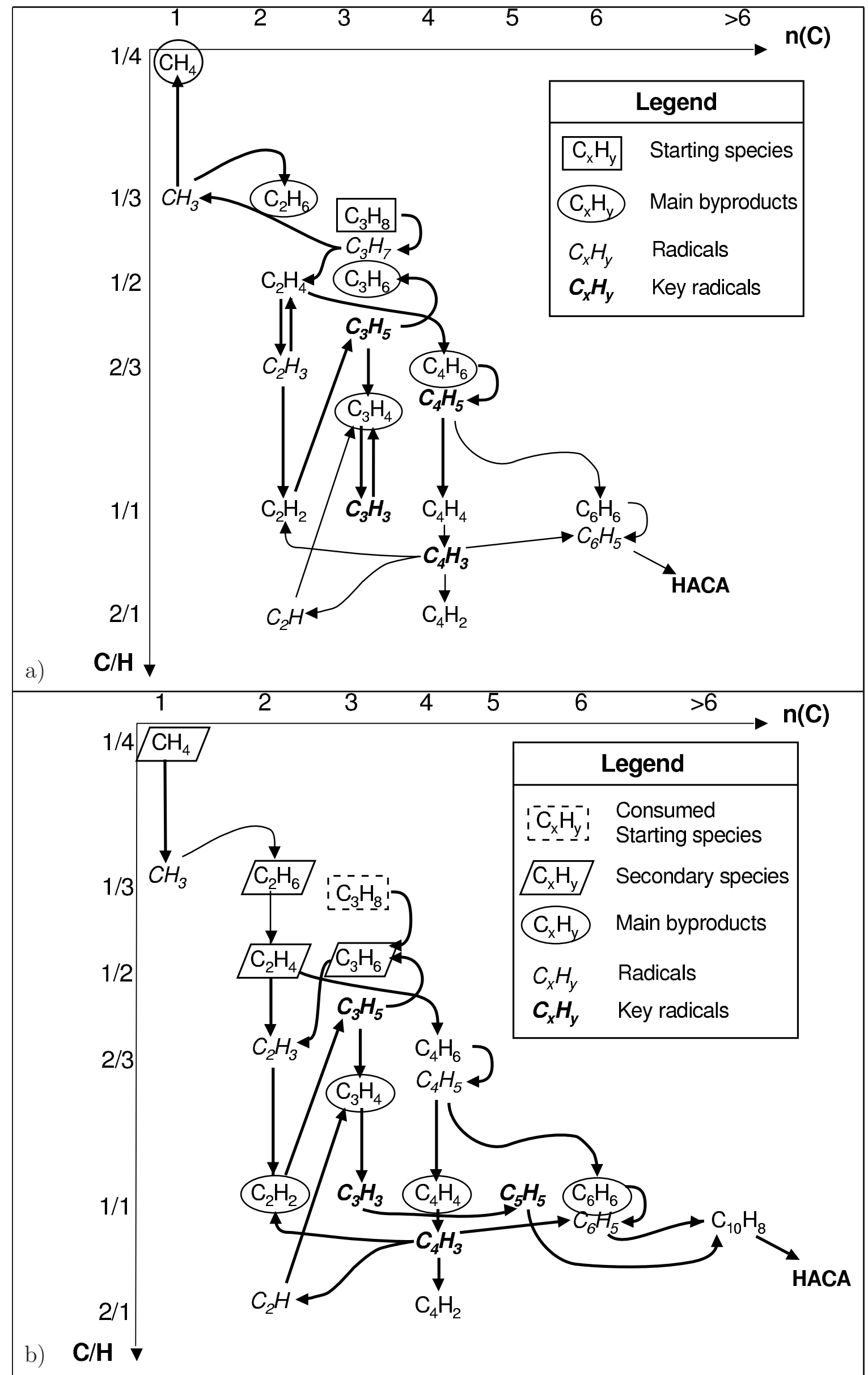

Figure 7: 


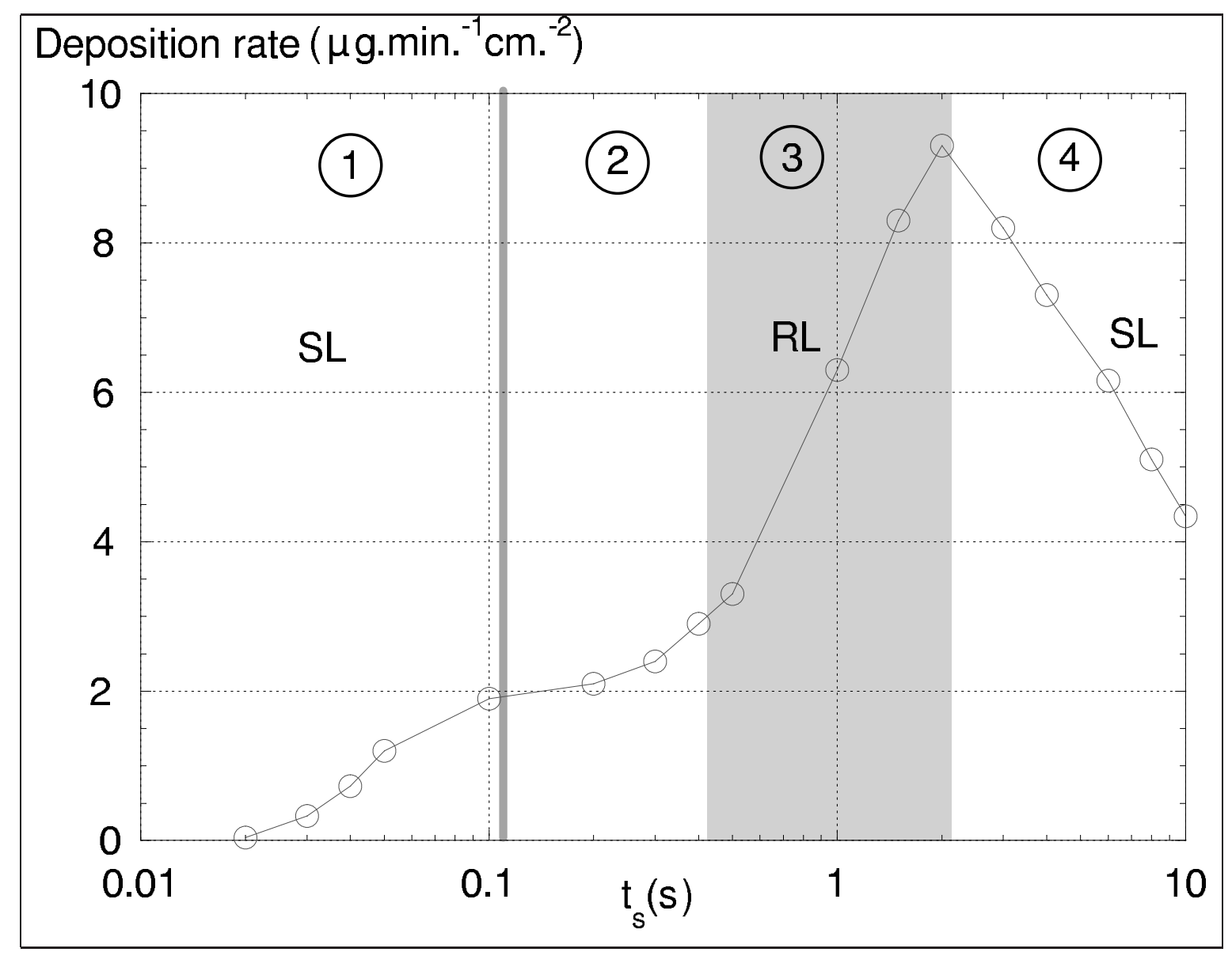

Figure 8: 


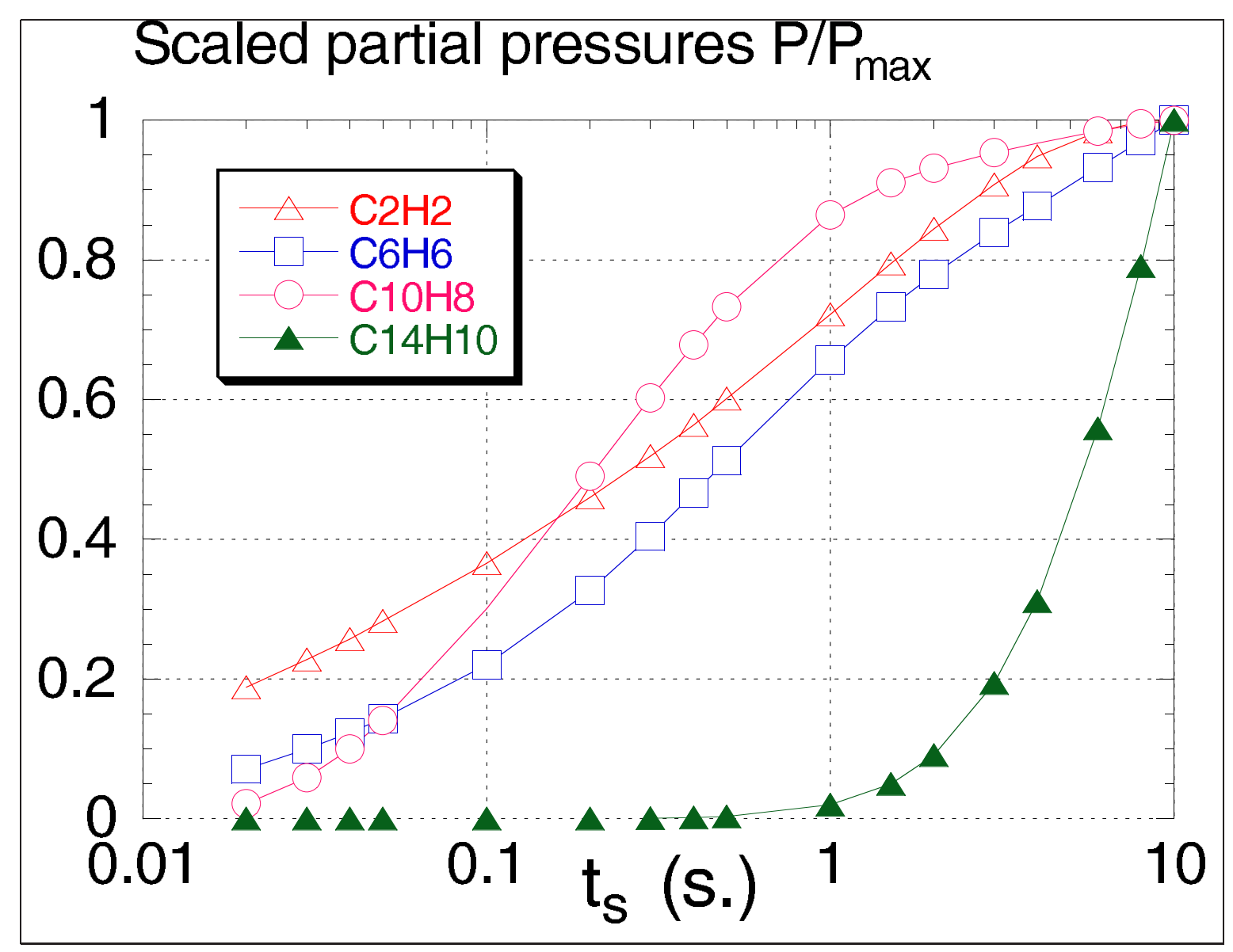

Figure 9: 


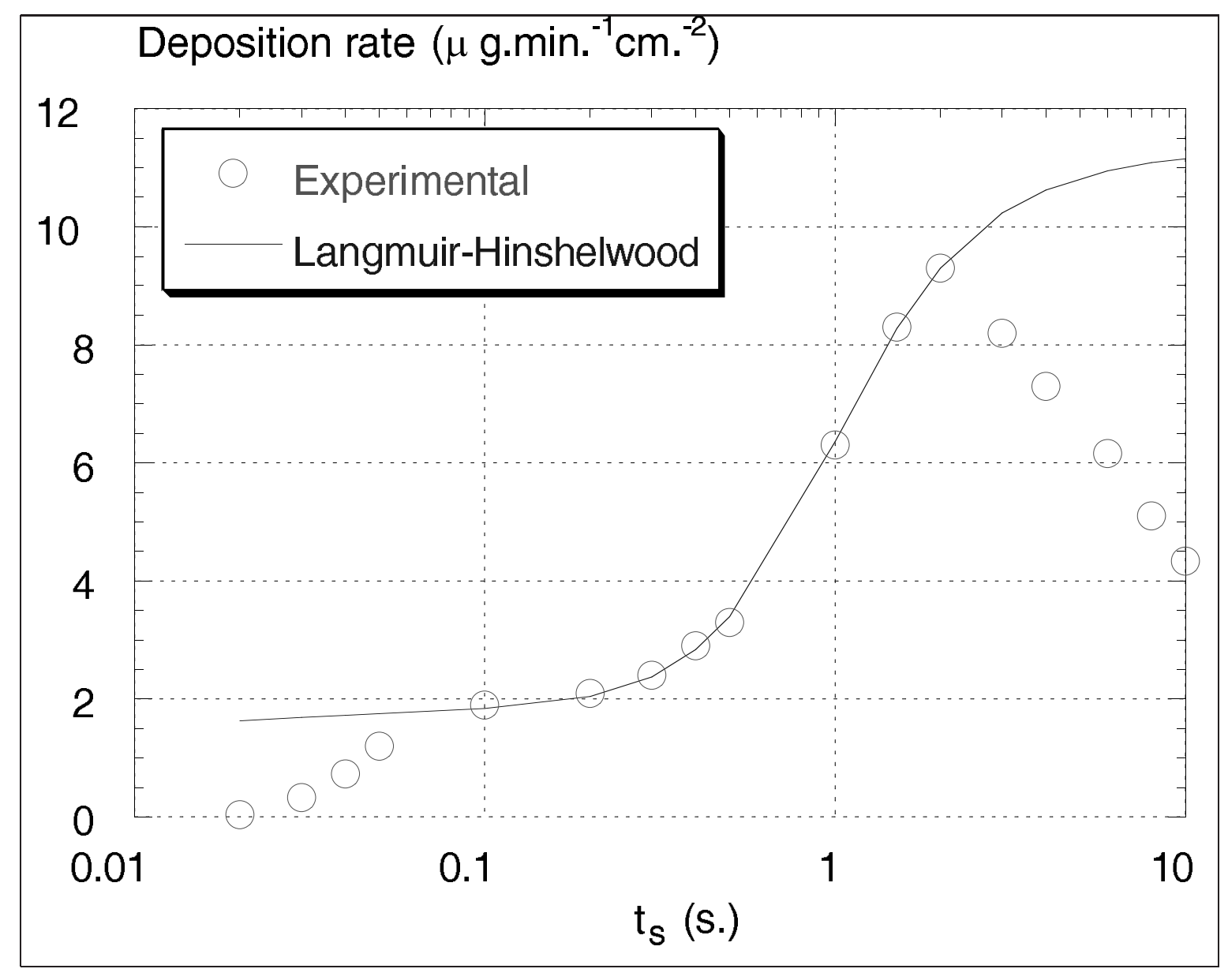

Figure 10: 


\begin{tabular}{|c|c|c|c|c|}
\hline Procedure & Mechanism & Validation & Analysis & Model scope \\
\hline Bibliography & $\begin{array}{c}\text { A } \\
61 \text { species } \\
746 \text { reactions }\end{array}$ & $\begin{array}{l}\text { Qualitative comparison } \\
\text { with FTIR data }\end{array}$ & $\begin{array}{l}\text { Trend } \\
\text { analysis }\end{array}$ & $\begin{array}{l}\text { Pertinent for } \\
\text { light species }\end{array}$ \\
\hline $\begin{array}{c}\text { Consumption } \\
\text { rates }\end{array}$ & $\begin{array}{c}\text { B1 } \\
40 \text { species } \\
390 \text { reactions }\end{array}$ & $\begin{array}{l}\% \text { error vs. } \\
\text { model A }\end{array}$ & $\begin{array}{l}\text { Reaction } \\
\text { rates }\end{array}$ & $\begin{array}{c}\text { coherent with } \\
\text { model A }\end{array}$ \\
\hline $\begin{array}{c}\text { Principal } \\
\text { component } \\
\text { analysis }\end{array}$ & $\begin{array}{c}\text { B2 } \\
40 \text { species } \\
136 \text { reactions }\end{array}$ & $\begin{array}{l}\% \text { error vs. } \\
\text { model A }\end{array}$ & $\begin{array}{l}\text { Identification of } \\
\text { reaction sequences }\end{array}$ & $\begin{array}{c}\text { coherent with } \\
\text { model A }\end{array}$ \\
\hline Bibliography & $\begin{array}{c}\mathrm{C} \\
53 \text { species } \\
205 \text { reactions }\end{array}$ & $\begin{array}{c}\text { Qualitative comparison } \\
\text { with FTIR data }\end{array}$ & $\begin{array}{l}\text { Analysis of } \\
\text { reaction fluxes }\end{array}$ & $\begin{array}{l}\text { Pertinent for } \\
\text { heavier species }\end{array}$ \\
\hline Langmuir & $\begin{array}{c}\text { D } \\
53 \text { species } \\
209 \text { reactions }\end{array}$ & $\begin{array}{c}\text { Comparison } \\
\text { with mass uptake data }\end{array}$ & & $\begin{array}{l}\text { Correlation } \\
\text { attempt }\end{array}$ \\
\hline
\end{tabular}

Table 1: 